\title{
DIRECT DISPLACEMENT-BASED SEISMIC DESIGN OF CONCRETE BUILDINGS
}

\author{
M.J.N. Priestley ${ }^{1}$ and M.J. Kowalsky ${ }^{2}$
}

\begin{abstract}
A seismic design procedure is developed to enable concrete buildings to be designed to achieve a specified acceptable level of damage under the design earthquake. The acceptable limit is defined as a displacement profile related to limit material strains or code specified drift limits. In this procedure, the elastic properties, including initial stiffness, strength and period, are the end product of the design rather than the starting point.

It is shown that the procedure is simple to apply, and results in significant differences from the more conventional force-based procedure. Designs for multi-storey frame and wall buildings are presented, and target displacements are compared with results from inelastic time-history analysis.
\end{abstract}

\section{INTRODUCTION}

In recent years there has been extensive examination of the current seismic design philosophy, which is based on provision of a required minimum strength, related to initial stiffness, seismic intensity, and a force reduction, or ductility factor considered to be a characteristic of a particular structural system and construction material. In the case of NZS4203(1) and NZS3101(2), there has been a great deal of effort, based largely on well-focused research at the Universities of Canterbury and Auckland, to ensure that detailing of concrete structures is adequate to ensure that the designed structure can survive the design level of seismicity without sustaining excessive damage. It could thus be argued that the goals of "performance-based" seismic design are already met by New Zealand seismic design practice.

To a larger extent this is true, and it is not unreasonable to characterize overseas developments in seismic design, particularly in the USA and Europe, as efforts to obtain levels of safety and consistency similar to that which has been available in New Zealand since the early 1980's. Despite this rather satisfactory situation, it is clear that there is still considerable room for improvement in seismic design in New Zealand. This is largely the result of the inappropriateness of the two fundamental assumptions of force-based design: (1) that the initial stiffness of a structure determines its displacement response and (2) that a ductility capacity can be assigned to a structural system regardless of its geometry, member strength, and foundation conditions.

In recent papers published in the NZSEE Bulletin (3), (4), these fundamental assumptions have been critically examined. In particular, it has been shown that the assumption that the stiffness of reinforced concrete members at first yield can be considered independent of strength is invalid. Over the typical range of reinforcement ratios and axial load levels, it is more reasonable to assume that stiffness is proportional to strength. That is,

$$
\mathrm{I}_{\mathrm{eff}}=\mathrm{kM}_{\mathrm{N}}
$$

where $I_{\mathrm{c} f r}$ is the effective moment of inertia of the section, $\mathrm{M}_{\mathrm{N}}$ is the nominal flexural strength, and $\mathrm{k}$ is a constant. Since the yield curvature $\phi_{\text {, can be expressed as }}$

$$
\phi_{y}=\frac{M_{N}}{E_{c} I_{e f f}}=\frac{1}{k E_{c}}
$$

where $E_{c}$ is the concrete modulus of elasticity, the implication of Eqn. (2) is that the yield curvature is a function of the section geometry, independent of strength.

In fact, the research described in references (3) and (4) approached the argument inversely, showing that the yield curvature of sections are dependent only on geometry, and that, hence, stiffness is proportional to strength. The results of the research can be summarized by the following dimensionless relationships:

\footnotetext{
${ }^{1}$ University of California, San Diego, California (Fellow \& Ex-President)

${ }^{2}$ University of California, San Diego (Member)
} 
Beams (rectangular or flanged):

$$
h_{y} \phi_{y}=1.70 \varepsilon_{y} \quad \pm 10 \%
$$

Circular columns:

$$
D \phi_{y}=2.35 \varepsilon_{y} \quad \pm 15 \%
$$

Rectangular columns:

$$
h_{y} \phi_{y}=2.12 \varepsilon_{y} \quad \pm 10 \%
$$

Rectangular walls:

$$
\ell_{w} \phi_{y}=2.00 \varepsilon_{y} \quad \pm 10 \%
$$

where $h_{b}, D, h_{c}$ and $\ell_{w}$ are the beam depth, column diameter, column depth and wall length of the sections, respectively, and $\varepsilon_{y}=f_{y} / E_{s}$ is the yield strain of the longitudinal reinforcement in the section.

It was further shown(4) that the storey yield drift $\theta_{y}$ of reinforced concrete frames could be expressed in the form

$$
\theta_{y}=0.5 \varepsilon_{y} \ell_{b} / h_{b}
$$

where $\ell_{b}$ is the beam bay length. Calibrating Eqn. (4) against experimental results from more than 40 beam-column test units showed surprisingly little scatter, with the mean experiment/prediction ratio being 1.03 , with a $16 \%$ coefficient of variation (4).

The proportionality between strength and stiffness implied by Equations (1-3) calls into question the fundamental assumption of force-based design: that an initial stiffness, and hence building period can be determined independent of strength, and that strength can then be apportioned between members in proportion to the initial assumed stiffness. Clearly, unless a serendipitous choice of stiffness is made for all elements initially, the action of allocating strength will change the stiffness values from the initial assumption. This would at least imply the need for iterative analysis to determine required strengths.

A second assumption implicit in force-based design is that structures can be designed so that their lateral force-resisting elements (walls, frames) can be designed such that they yield simultaneously. Examination of Eqn. (3d) indicates that this assumption is invalid for parallel walls of different lengths and Eqn. (4) indicates that it will also be invalid for parallel frames with different beam depths or bay lengths. Equation (4) also indicates that it will be impossible to ensure that beams in a frame with different bay lengths yield simultaneously, unless beam depth is varied in proportion to bay length.

A third outcome from the research summarized in (3) and (4) is that yield drifts of structures are generally grossly underestimated in current design approaches. As a consequence, code drift limits tend to reduce design ductility levels to values significantly less than the maximum values permitted by NZS3101. For example, Eqn. (4) implies that for $\mathrm{f}_{\mathrm{y}}=400 \mathrm{MPa}$, and $\ell_{b} / h_{b}=10$, the yield drift will be $\theta_{y}=0.01$. With a drift limit at maximum response of 0.02 , this implies a maximum usable ductility of only 2 , and hence significantly increased seismic forces, than are generally provided.

\section{DIRECT DISPLACEMENT-BASED DESIGN}

It is generally accepted that damage is best characterized by strain and deformation limits. For example, at the serviceability limit state, concrete compression strains should be lower than the strain at which incipient spalling occurs - a conservative limit of $\varepsilon_{\mathrm{c}}=0.004$ has been suggested (6) - and reinforcement tension strains should be such that residual crack widths should be less than that requiring crack grouting after the earthquake. Dependant on exposure and axial load, peak tensile strains of $\varepsilon_{\mathrm{s}}=0.010$ to 0.015 are appropriate. To limit non-structural damage, interstorey drifts might be limited to 0.01 . These limits, and corresponding ones for the damage control limit state, are discussed subsequently.

It would appear that a design approach that attempts to design a structure which would achieve, rather than be bounded by. a given limit state under a given seismic intensity would be desirable. This would essentially result in uniform-risk structures, which is philosophically compatible with the uniform-risk seismic intensity incorporated in most codes. Note that force-based design does not attempt to produce uniform-risk structures, but attempts to keep the risk for a given structure below an acceptable threshold, albeit undefined. It can easily be shown that risk, in terms of annual probability of a given level of damage, for structures designed to force-based criteria, can vary by more than an order of magnitude from structure to structure.

While force-based design characterizes a structure in terms of elastic properties (stiffness, damping) appropriate at first yield, direct displacement-based design characterizes the structure by secant stiffness $\mathrm{K}_{\mathrm{c}}$ at maximum displacement $\Delta_{\mathrm{d}}$ (Fig. 1(b)) and a level of equivalent viscous damping appropriate to the hysteretic energy absorbed during inelastic response. Thus, as shown in Figure 1(c), for a given level of ductility demand, a structural steel building with compact members will be assigned a higher level of equivalent viscous damping than a reinforced concrete structural wall building designed for the same level of ductility demand, as a consequence of "fatter" hysteresis loops. The approach used to characterize the structure is based on the "substitute structure" analysis procedure developed by Shibata and Sozen (5) in the 1970's.

With the design displacement $\Delta_{\mathfrak{d}}$ determined, as discussed subsequently, and the damping estimated from the expected ductility demand, the effective period $T_{c}$ at maximum displacement response can be read from a set of design displacement spectra, as shown in the example of Figure 1(d). Representing the structure (Fig. 1(a)) as an equivalent SDOF oscillator, the effective stiffness $K_{c}$ at maximum response displacement can be found by inverting the equation for natural period of a SDOF oscillator, namely

$$
T_{e}=2 \pi \sqrt{\frac{m_{e}}{K_{e}}}
$$

to provide 


$$
K_{e}=4 \pi^{2} m_{e} / T_{e}^{2}
$$

where $m_{e}$ is the effective mass.

From Figure 1(b), the design base shear at maximum response is thus

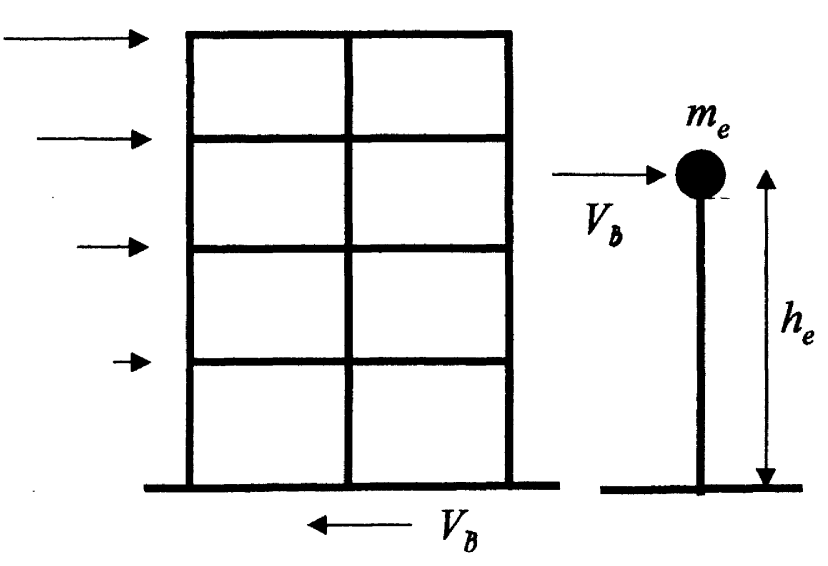

(a) SDOF Simulation

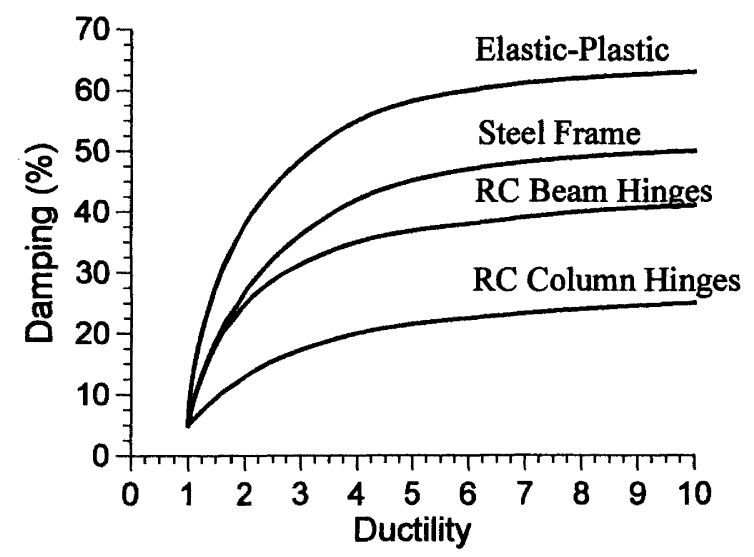

(c) Equivalent damping vs. ductility

$$
\mathrm{V}_{\mathrm{B}}=\mathrm{F}_{\mathrm{u}}=\mathrm{K}_{\mathrm{e}} \Delta_{\mathrm{d}}
$$

The design concept is thus very simple, and such complexity as exists relates to determination of the "substitute structure" characteristics, determination of the design displacement and development of design displacement spectra.

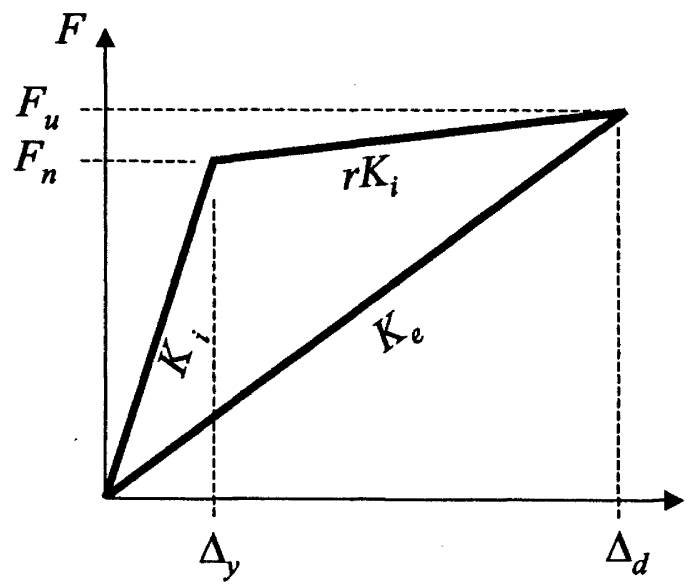

(b) Effective stiffness, $K_{e}$

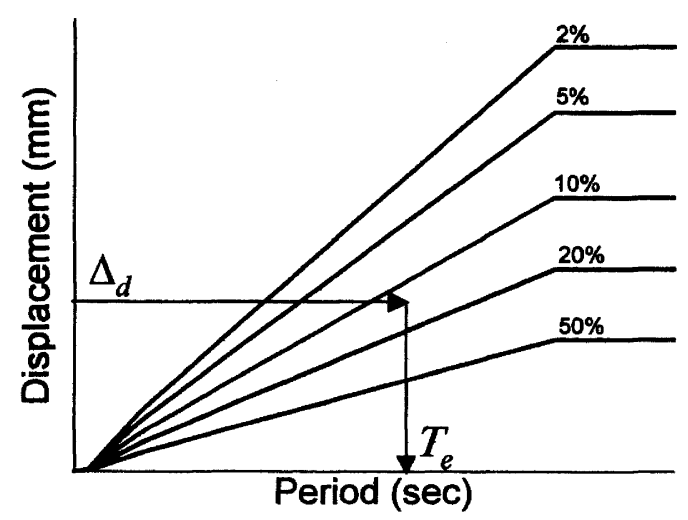

(d) Design displacement response spectra

Figure 1: Fundamentals of Direct Displacement-based Design.

\section{Design Limit States}

Two limit states might be considered: the serviceability limit state, and the damage control limit state. In NZS4203 the former is equated with a structural displacement ductility of $\mu_{\Delta}=1$. This, however, is generally conservative, and provides uneven protection against a level of damage requiring repair, which would appear to be a reasonable definition of a serviceability limit. Thus crushing of concrete, and unacceptably large residual crack widths might define the serviceability limit state for concrete and masonry structures. Note that it is the residual crack width, rather than the maximum occurring during seismic response which is of principal interest. Limit compression strains of 0.004 would appear reasonable for both concrete and masonry. Maximum reinforcement tensile strains of 0.01 for beams and 0.015 for columns and walls seem appropriate, since analysis of test data indicates that residual crack widths of reinforced concrete members subjected to peak strains of this level will be in the range $0.5-1.0 \mathrm{~mm}$.

The definition of a serviceability drift limit is less obvious, since the onset of non-structural damage is very dependent on the design details provided to separate non-structural elements from structural elements. More work is required in this area. However with good detailing non-structural damage should not be evident at drifts of less than $\theta=0.01$. 
The damage-control limit state can also be defined by material strain limits and by design drift limits intended to restrict non-structural damage. For example, a limit compression strain for confined concrete of

$$
\varepsilon_{c m}=0.004+\left(1.4 \rho_{s} f_{y h} \varepsilon_{s u h}\right) / f_{c c}^{\prime}
$$

is felt to be conservative, where the confinement reinforcement has volumetric ratio $\rho_{\mathrm{s}}$, yield strength $\mathrm{f}_{\mathrm{yh}}$ and strain at maximum stress $\varepsilon_{\text {suls }}$, and $f^{\prime}$ cc is the compression strength of the confined concrete (6).

The maximum longitudinal reinforcement tensile strain $\varepsilon_{\mathrm{sm}}$ must be limited to a lesser value than the strain $\varepsilon_{\mathrm{su}}$ at maximum stress to avoid buckling and low cycle fatigue. It is suggested that

$$
\varepsilon_{\mathrm{sm}}=0.6 \varepsilon_{\mathrm{su}}
$$

It is comparatively straightforward to compute drift limits from strain limits. For example, and with reference to Figure 2 , the maximum drift corresponding to material strain limits will be the lesser of

$$
\begin{aligned}
\theta_{m c}=\theta_{y}+\left(\frac{\varepsilon_{c m}}{c}-\phi_{y}\right) \ell_{p} & \\
\theta_{m s}=\theta_{y}+ & \left.\frac{\varepsilon_{s m}}{(d-c)}-\phi_{y}\right) \ell_{p} \\
& \quad(\text { reinforcement tension) } 10(\mathrm{~b})
\end{aligned}
$$

and

where $\theta_{\mathrm{y}}$ is the yield drift, and $\ell_{\mathrm{p}}$ the plastic hinge length.

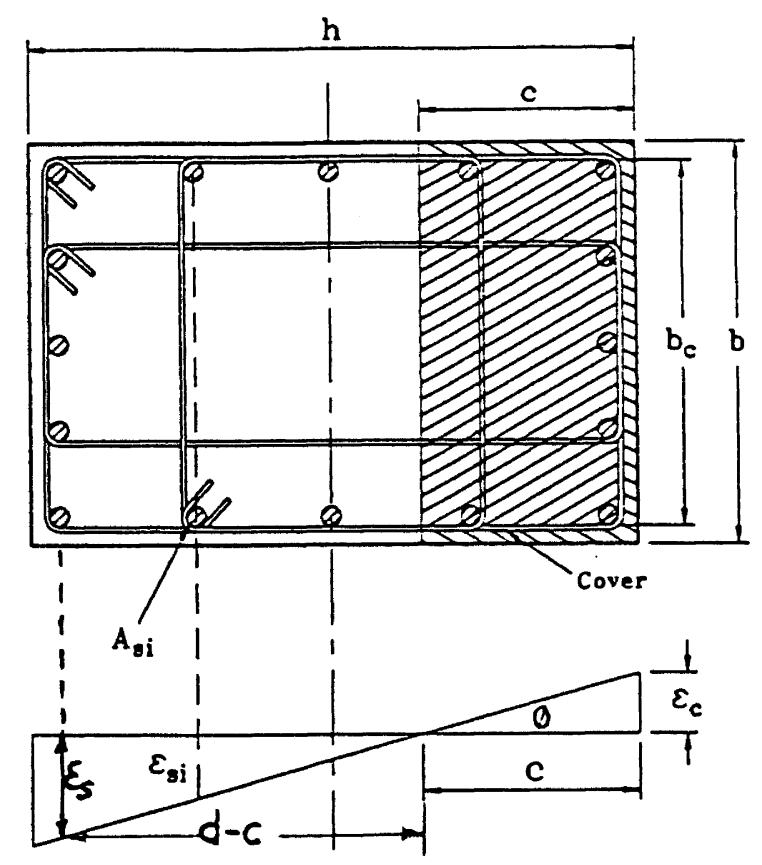

Figure 2: Strain profile for a rectangular section.
The material drift limits of Eqn. 10 would be compared with the code drift limits imposed to limit non-structural damage, and the more critical adopted for design. In almost all reinforced concrete structures, whether designed with walls or frames, it is likely to be the code drift limits that control the design drift.

\section{Design Displacement Spectra}

A major difference from force-based design is that design utilizes a set of displacement-response spectra (e.g. Fig. 1(d)) for different levels of equivalent viscous damping, rather than the acceleration-response spectra for $5 \%$ damping adopted by most force-based codes. Since the structural period of the substitute structure is longer than that for the elastic structure (i.e. $\mathrm{T}_{\mathrm{e}} \approx \sqrt{\mu} \mathrm{T}_{\mathrm{i}}$, where $\mathrm{T}_{\mathrm{i}}$ is the initial, elastic period), it is necessary for the displacement spectra to continue to longer periods than commonly plotted for acceleration spectra. It is also appropriate to place a cap on peak response displacements, since at long periods, structural displacements tend to reduce, eventually equaling the peak ground displacement. The European seismic code EC8 (7) adopts a cap at $\mathrm{T}=3 \mathrm{sec}$. above which displacements are considered to be independent of period. Geotechnical considerations indicate that the cap period should depend on the foundation conditions, with lower periods applying for rock than for soft soil.

Figure 3 shows displacement spectra derived from New Zealand code acceleration spectra for different soil conditions and a peak effective ground acceleration of $0.4 \mathrm{~g}$. Spectra for other than $5 \%$ damping have been determined using the EC 8 modification factor of

$$
\Delta_{(T, \xi)}=\Delta_{(T, 5)}\left(\frac{7}{2+\xi}\right)^{\frac{1}{2}}
$$

where $\xi$ is the damping, expressed as a percentage of critical damping, for the design limit state being considered.

Based on this, it appears reasonable, and within the level of uncertainty inherent in formulation of design spectra, to adopt linear displacement spectra. The small non-linearity at low periods is unlikely to be significant for displacement-based designs, since it is the longer period at peak response that is of relevance.

The effective linearity of the displacement response spectra enable the sequence of design steps described above to be combined into a simple design equation for base shear. Let $\Delta_{(P, 5)}$ be the displacement at peak period [e.g. $T_{p}=4 \mathrm{sec}$ ] for displacement, corresponding to $5 \%$ damping. From Eqn. 11, the corresponding displacement at $\mathrm{T}_{\mathrm{p}}$ for $\xi \%$ damping is

$$
\Delta_{(P, \xi)}=\Delta_{(P, 5)}\left[\frac{7}{2+\xi}\right]^{\frac{1}{2}}
$$

For a design displacement of $\Delta_{\mathrm{d}}$, and design damping $\xi$, the effective period at peak response is thus

$$
T_{e}=T_{p} \frac{\Delta_{d}}{\Delta_{(P, 5)}}\left[\frac{2+\xi}{7}\right]^{\frac{1}{2}}
$$


and, from Eqn. (6), the effective stiffness at peak response is

$$
K_{e}=\frac{4 \pi^{2} m_{e} \Delta_{(P, 5)}^{2}}{T_{P}^{2} \Delta_{d}^{2}}\left[\frac{7}{2+\xi}\right]
$$

Finally, from Eqn. (7):

$$
V_{B}=\frac{4 \pi^{2} m_{e}}{T_{P}^{2}} \frac{\Delta_{(P, 5)}^{2}}{\Delta_{d}}\left[\frac{7}{2+\xi}\right]
$$

Note that with reasonable accuracy the displacement at peak period $T_{p}$ can be found from the $5 \%$ aceleration spectral value $a_{p}$ as

$$
\Delta_{(P, 5)}=\frac{T_{p}^{2}}{4 \pi^{2}}\left(\mathrm{a}_{p}\right)=\frac{T_{p}^{2}}{4 \pi^{2}} C_{h}\left(T_{p}, 1\right) S_{p} Z g
$$

Where $C_{h}\left(T_{p} 1\right)$ is the basic seismic hazard acceleration coefficient for period $T_{p}$ and elastic response, $S_{p}$ is the structural performace factor, $\mathrm{Z}$ is the zone factor, and $\mathrm{g}$ is the acceleration due to gravity. Thus, in terms of the current NZS4203 formulation for seismicity, the design base shear at mazimum response can be expressed as

$$
V_{B}=\frac{m_{e}}{4 \pi^{2}} T_{p}^{2}\left[C_{h}\left(T_{p}, 1\right) S_{p} Z g\right]^{2}\left[\frac{7}{2+\xi}\right]
$$

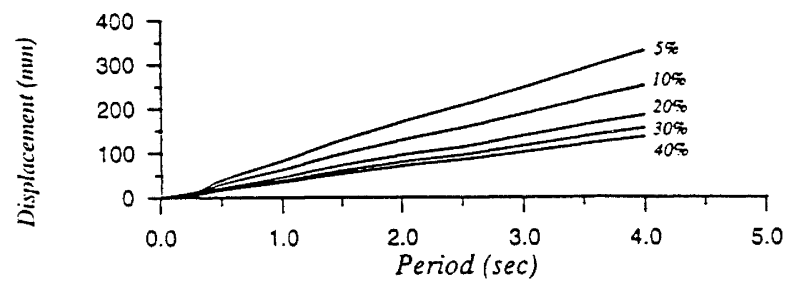

(a) Rock + Firm Soil

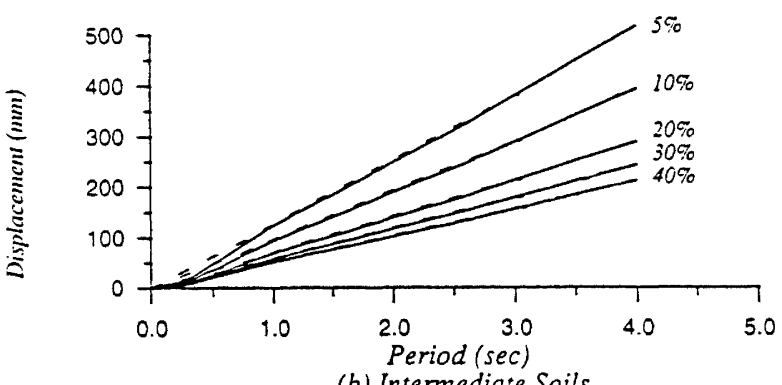

(b) Intermediate Soils

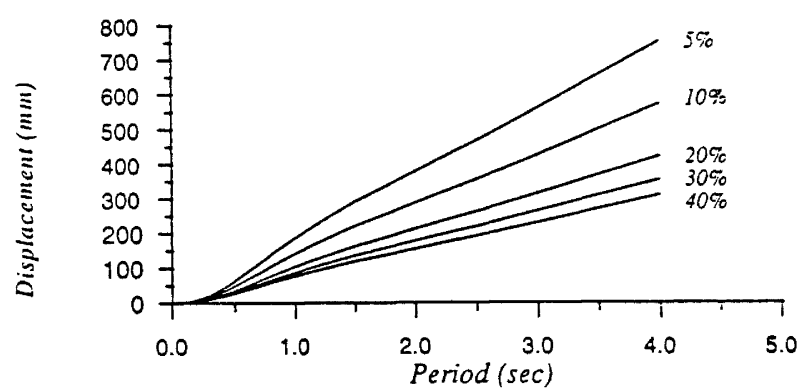

(c) Flexible or deep soil sites

Figure 3: Design displacement spectra to NZS4203(1992) and Equation 11.

\section{DESIGN OF MULTI-STOREY BUILDINGS}

Much of the literature relating to direct displacement-based seismic design has thus far concentrated on single or multidegree of freedom bridge structures $(8,9,10)$. Dynamic analyses of bridge structures have demonstrated that the design procedure is capable of producing structures that, when subjected to dynamic inelastic time-history analysis under spectrum-compatible earthquake records, will respond with peak displacements close to the chosen design displacement.

In the remainder of this paper, design procedures appropriate for multi-storey reinforced concrete frame and structural wall buildings are presented.

Equivalent Single-Degree-Of Freedom Model (Substitute Structure)

It is evident from the previous discussion that the design procedure requires initial determination of the design displacement, and the effective mass and damping of the equivalent SDOF substitute structure.

\section{Design Displacement}

In many cases, the design displacement will be dictated by code drift limits, as previously discussed. In general, however, the peak drift can be expressed as

$$
\theta_{d}=\theta_{y}+\theta_{p} \leq \theta_{c}
$$

where the design drift $\theta_{d}$ is comprised of elastic $\left(\theta_{y}\right)$ and plastic components $\left(\theta_{\mathrm{p}}\right)$ and must not exceed the code limit $\theta_{c}$. As illustrated in Figure 4, the critical location for $\theta_{d}$ is likely to be at the lower floors of a frame building, and the top floor of a structural wall building. For illustrative reasons, and because of space limitations, only the damage control limit state will be considered in the following. For frame structures, the elastic yield drift is given by Eqn. 4, and the plastic drift by

$$
\theta_{p}=\left(\phi_{m}-\phi_{y}\right) \ell_{p} \cdot\left[\frac{\ell_{c}}{\ell_{b}}\right]
$$

where $\phi_{m}$ is the critical curvature from Eqn. 10(a) or 10(b) and $\ell_{c} \& \ell_{b}$ are the clear beam lengths between column faces and the beam length from column centre to centre respectively. In many cases it will be more appropriate to select a design ductility limit of $\mu=\left(\theta_{y}+\theta_{p}\right) / \theta_{y}$ based on the extensive research database of beam/column joint subassemblage testing, rather than calculating the plastic curvature based on an estimated plastic hinge length $\ell_{\mathrm{p}}$ and an estimated maximum curvature. In this case, Eqn. 18 simplifies to

$$
\theta_{\mathrm{d}}=\mu \theta_{\mathrm{y}} \leq \theta_{\mathrm{c}}
$$

Based on the research database, values in the range $4 \leq \mu \leq 6$ appear appropriate for well detailed beam plastic hinges. It is again emphasized, however, that unless the frames are unusually deep-membered, and low strength reinforcement is used, then the code drift limit will govern. 


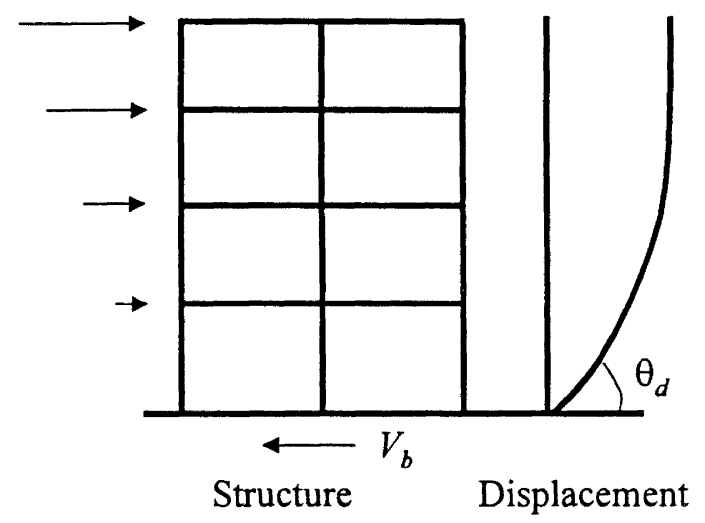

(a) Frame

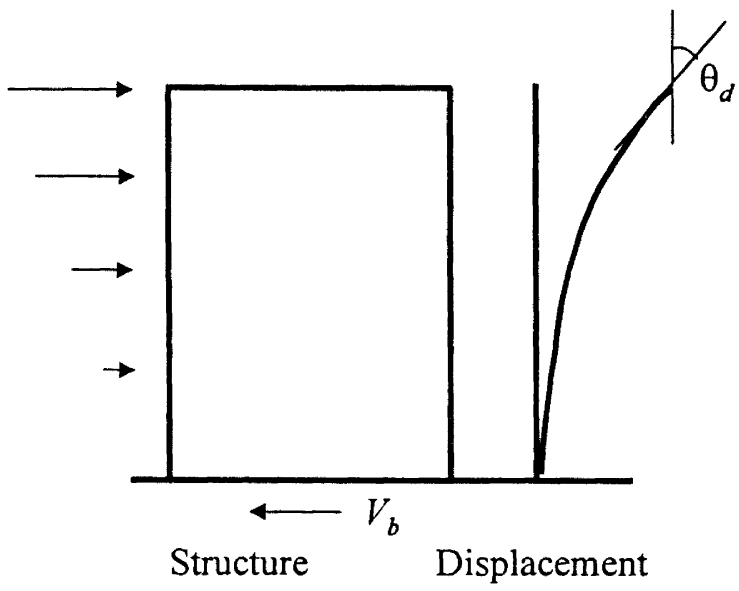

(b) Wall building

Figure 4: Critical drifts for building structures.

Having determined the critical drift, the design displacements $\Delta_{i}$ at different storeys, (i), can be estimated from characteristic displacement profiles at maximum response based on inelastic time-history analysis (11). The following equations, though approximate, have been shown to be adequate for design purposes (10):

With reference to Fig. 4(a),

for $\mathrm{n} \leq 4: \quad \Delta_{\mathrm{i}}=\theta_{\mathrm{d}} \mathrm{h}_{\mathrm{i}}$

$4 \leq \mathrm{n}<20: \quad \Delta_{\mathrm{i}}=\theta_{\mathrm{d}} \mathrm{h}_{\mathrm{i}}\left(1-\frac{0.5(\mathrm{n}-4) \mathrm{h}_{\mathrm{i}}}{16 \mathrm{~h}_{\mathrm{n}}}\right)$

$\mathrm{n} \geq 20: \quad \Delta_{\mathrm{i}}=\theta_{\mathrm{d}} \mathrm{h}_{\mathrm{i}}\left(1-0.5 \mathrm{~h}_{\mathrm{i}} / \mathrm{h}_{\mathrm{n}}\right)$

where $\mathrm{n}$ is the number of storeys.

For cantilever wall buildings, (Fig. 4(b)), the critical drift occurs at the top of the building. From Eqn. 3(d) assuming a linear distribution of curvature with height,

$$
\theta_{\mathrm{y}}=1.0 \varepsilon_{\mathrm{y}} \mathrm{h}_{\mathrm{n}} / \ell_{\mathrm{w}}
$$

and hence Eqn. 18 becomes

$$
\theta_{\mathrm{d}}=1.0 \varepsilon_{\mathrm{y}} \mathrm{h}_{\mathrm{n}} / \ell_{\mathrm{w}}+\left(\phi_{m}-\phi_{y}\right) \ell_{\mathrm{p}} \leq \theta_{\mathrm{c}}
$$

Analyses of typical wall sections (3) indicated that, for given limit strains, the limit state curvature is rather insensitive to axial load and reinforcement ratio. For example, it was found that the damage-control limit state curvature, based on limit strains of $\varepsilon_{\mathrm{cm}}=0.018$, and $\varepsilon_{\mathrm{sm}}=0.06$ could be expressed as

$$
\phi_{m}=0.072 / \ell_{w} \pm 10 \%
$$

The plastic drift, $\theta_{\mathrm{p}}$, can then be expressed as

$$
\theta_{p}=\left(\phi_{m}-\phi_{y}\right) \ell_{p}
$$

where $\phi_{y}$ is given by Eqn. 3(d), and the plastic hinge length $\ell_{\mathrm{p}}$ may be taken as (11) the larger of

$$
\begin{aligned}
& \ell_{\mathrm{p}}=0.2 \ell_{\mathrm{w}}+0.03 \mathrm{~h}_{\mathrm{n}} \\
& \ell_{\mathrm{p}}=0.054 \mathrm{~h}_{\mathrm{n}}+0.022 f_{\mathrm{y}} \mathrm{d}_{\mathrm{h}}
\end{aligned}
$$

where $\mathrm{h}_{\mathrm{n}}$ is the roof height, and $\mathrm{d}_{\mathrm{h}}$ and $f_{\mathrm{y}}$ are the diameter and yield stress of the wall vertical reinforcement.

The design displacement profile is thus

$\Delta_{i}=\Delta_{e i}+\Delta_{p i}$

$=\frac{2}{3} \varepsilon_{y} \frac{h_{i}^{2}}{\ell_{w}}\left(1.5-\frac{h_{i}}{2 h_{n}}\right)+\left(\theta_{d}-\frac{\varepsilon_{y} h_{n}}{\ell_{n}}\right)\left(h_{i}-\frac{\ell_{p}}{2}\right)$

Having found the design displacement profile from Eqn. 20 or 26 for frames and walls, respectively, the design displacement for the equivalent SDOF system is

$$
\Delta_{\mathrm{d}}=\sum_{\mathrm{i}=1}^{\mathrm{n}}\left(\mathrm{m}_{\mathrm{i}} \Delta_{\mathrm{i}}{ }^{2}\right) / \sum_{\mathrm{i}=1}^{\mathrm{n}}\left(\mathrm{m}_{\mathrm{i}} \Delta_{\mathrm{i}}\right)
$$

where $m_{i}$ are the storey masses.

\section{Effective Mass}

From consideration of mass participation in the fundamental mode, the effective system mass for the equivalent SDOF system is

$$
m_{e}=\sum_{i=1}^{n}\left(m_{i} \Delta_{i}\right) / \Delta_{d}
$$

Note that this will differ slightly from the mass participating in the first elastic mode, since it is the inelastic displaced shape that is used.

Typically,

$$
m_{e} \approx 0.7 \sum m_{i}
$$




\section{Effective Damping}

The effective damping depends on the structural system and ductility, as illustrated in Figure 1(c). Thus an estimate is needed of the ductility before the design proceeds. This is straightforward, since the work described earlier in this paper establishes that the dimensionless yield curvatures of concrete structural systems are independent of strength. Note that the same conclusion is also obviously valid for steel members: the yield curvature can be expressed as

$$
\phi_{y}=2 \varepsilon_{\mathrm{y}} / \mathrm{h}_{\mathrm{b}}
$$

regardless of the width or depth of the flanges, within normal limits of symmetrical steel sections.

The yield displacement at the height of the resultant lateral seismic force may thus be found, with adequate accuracy as follows:

$$
\begin{array}{ll}
\text { Walls: } & \Delta_{y}=\frac{2.0 \varepsilon_{y}}{3 \ell_{w}}\left(0.7 h_{n}\right)^{2} \\
\text { Frames: } & \Delta_{\mathrm{y}}=0.5 \varepsilon_{\mathrm{y}}\left(\frac{\ell_{\mathrm{b}}}{\mathrm{h}_{\mathrm{b}}}\right)\left(0.6 \mathrm{~h}_{\mathrm{n}}\right)
\end{array}
$$

where the height of the resultant lateral force is approximated as $0.7 h_{n}$ and $0.6 h_{n}$ for wall and frame structures, respectively. Although these heights are adequate for regular structures, a more precise determination of effective height should be made when mass or storey heights vary significantly with height. In this case, the effective height $h_{e}$ should be taken as

$$
h_{e}=\sum_{i=1}^{n}\left(m_{i} \Delta_{i} h_{i} / \sum_{i=1}^{n} m_{i} \Delta_{i}\right)
$$

The design ductility can now be determined from

$$
\mu_{\mathrm{s}}=\Delta_{\mathrm{d}} / \Delta_{\mathrm{y}}
$$

where $\Delta_{\mathrm{d}}$ is given by Eqn. 28 . The effective damping can then be read from the appropriate ductility/damping curve (e.g. Fig. 1(c)).

When the lateral resistance of a building in a given direction is comprised of a number of walls of different lengths, the ductility demand of each wall will differ, since the yield curvatures, and hence yield displacements of the walls are inversely proportional to wall length (Eqn. 3d), while the maximum displacements will be essentially equal, subject only to small variations resulting from torsional response. Hence the system damping will need to consider the different effective damping in each wall. Following the suggestion by Shibata and Sozen(5) that damping be weighted in proportion to flexural strain energy, and recognizing the displacement of all walls to be equal, a weighted mean average given by Eqn. 35 is appropiate.

$$
\xi_{\mathrm{e}}=\sum_{\mathrm{j}=1}^{\mathrm{m}}\left(\mathrm{V}_{\mathrm{j}} \xi_{\mathrm{j}}\right) / \sum_{\mathrm{j}=1}^{\mathrm{m}} \mathrm{V}_{\mathrm{j}}
$$

where $V_{j}$ and $\xi_{j}$ are the base shear and damping of the $\mathrm{m}$ walls in a given direction. A rational design decision will be to apportion the base shear between the walls in proportion to the wall length squared. This will result in essentially constant reinforcement ratios between walls. Hence, Eqn. 35 can be rewritten

$$
\xi_{\mathrm{c}}=\sum_{\mathrm{j}=1}^{\mathrm{m}}\left(\ell_{\mathrm{wj}}^{2} \xi_{\mathrm{j}}\right) / \sum_{\mathrm{j}=1}^{\mathrm{m}} \ell_{\mathrm{wj}}^{2}
$$

Note that conventional force-based design would apportion the base shear between walls in proportion to the cube of the wall length, based on the invalid assumption that the walls could be made to achieve simultaneous yield. The consequence is that the longer walls end up more heavily reinforced than the shorter walls, which is irrational, and results in further imbalance in elastic stiffness.

Having determined the design displacement, effective mass and effective damping, the required base shear is found from the displacement spectra set, using Eqns. 13 and 15.

\section{Distribution Of Base Shear}

The base shear calculated in accordance with the above procedure should be vertically distributed in proportion to the vertical mass and displacement profiles. Thus

$$
\mathrm{F}_{\mathrm{i}}=\mathrm{V}_{\mathrm{B}}\left(\mathrm{m}_{\mathrm{i}} \Delta_{\mathrm{i}}\right) / \sum_{\mathrm{i}=1}^{\mathrm{n}}\left(\mathrm{m}_{\mathrm{i}} \Delta_{\mathrm{i}}\right)
$$

Similarity with force-based design will immediately be apparent. The difference is that the actual displacement profile, rather than a height-proportional displacement, is adopted. No additional force at the roof level is recommended. When capacity design principles are adopted and normal gravity load requirements for upper levels are enforced, it is rare to find excessive ductility demand developing at the upper floor levels under inelastic timehistory analyses (10).

\section{BUILDING ANALYSIS FOR DESIGN MOMENTS}

In order to determine the design moments at potential plastic hinge locations, the lateral force analysis of the structure under the force vector represented by Eqn. 37 should be based on member stiffnesses representative of conditions at maximum displacement response. This is an essential component of the substitute structure approach (5). For cantilever wall buildings, this can be simplified to distribution of the forces between walls in proportion to $\ell_{\mathrm{w}}{ }^{2}$, as suggested above, and the walls separately analyzed.

However, for frame and dual-system buildings, more care is needed. With frame buildings, the member stiffness should reflect the effective stiffness at maximum response, rather than the elastic cracked-section stiffness $I_{c r}$ usually adopted for force-based analysis. With a weak-beam/strong column design, beam members will be subjected to inelastic actions, and the appropriate stiffness will be

$$
\mathrm{I}_{\mathrm{b}}=\mathrm{I}_{\mathrm{cr}} / \mu_{\mathrm{b}}
$$

where $\mu_{\mathrm{b}}$ is the expected beam displacement ductility demand. Analyses have shown (10) that member forces are not particularly sensitive to the level of stiffness assumed, and thus it is acceptable to assume $\mu_{\mathrm{b}}=\mu_{\mathrm{s}}$, the frame design ductility.

Since the columns will be protected against inelastic action by capacity design procedures, their stiffness should be $I_{c r}$ 
with no reduction for ductility. An exception exists for the ground floor column, where plastic hinges will normally be expected at the base level, but not at first floor level. It has been found (10) that the most effective way to model this is to place a hinge at the base level, and apply a base resisting moment $M_{B}$ to the hinge, while representing the column by the elastic cracked-section stiffness. This is illustrated in Fig. 5(a). The values of $M_{B}$ placed at the base hinges are, to some extent, the designers choice, since analysis of the structure under the lateral force vector together with the chosen column base moments $M_{B}$ will ensure a statically admissible equilibrium solution for design moments. In fact this freedom, implying some moment redistribution between beam hinges and column base hinges, allows the designer to improve the structural efficiency. A common choice will be to choose base moments such that the point of contraflexure in the lower storey columns occurs between $55 \%$ and $65 \%$ of the storey height above the base, thus ensuring capacity protection against hinging at the top of the ground floor columns, and an advantageous distribution of moments above and below the first level beams.

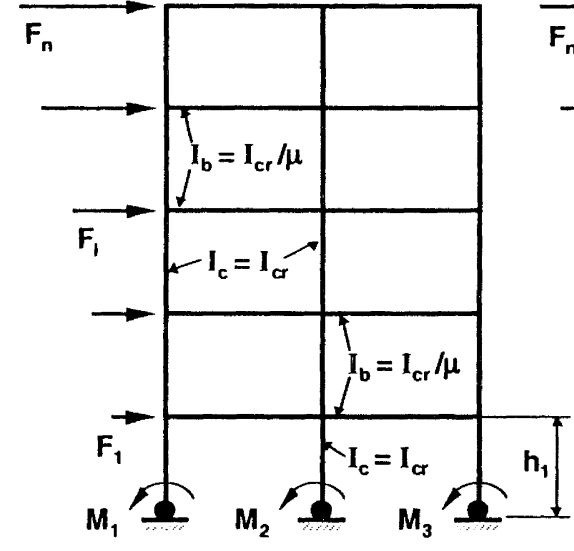

(a) Frame Building

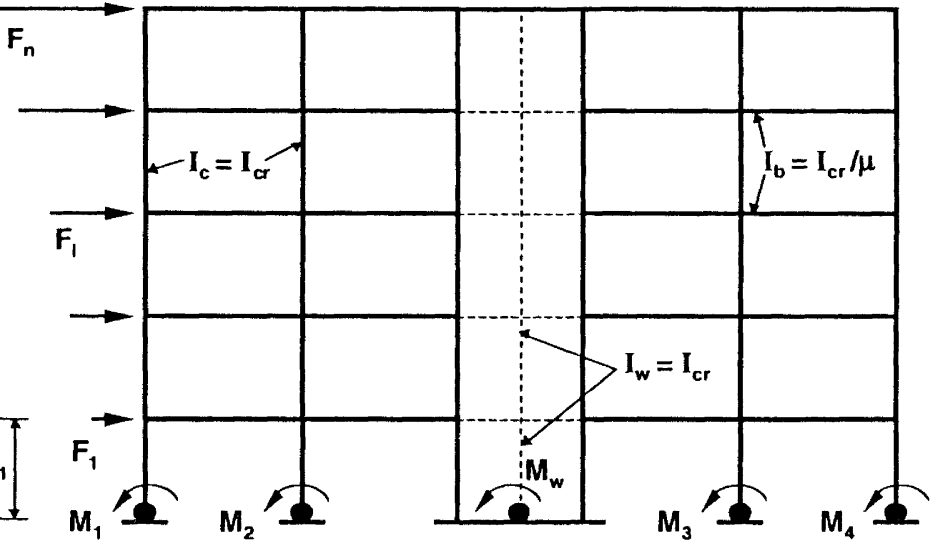

(b) Dual System

Figure 5: Member stiffness for substitute structure analyses.

With a point of contraflexure chosen at $60 \%$ of the column height $h_{1}$ (to beam centerline), and with reference to Fig. 5(a) equilibrium requires that

$$
\sum M_{B}=M_{1}+M_{2}+M_{3}=V_{B}\left(0.6 h_{i}\right)
$$

Assuming $h_{b}=0.15 h_{1}$, the column moments at the base of the first floor beams will be $54 \%$ of those at the column base, providing adequate protection for increased column moment resulting from strain hardening and higher mode effects. Strictly, the distribution of $\sum M_{B}$ should reflect the variation in column stiffness caused by the seismically induced axial loads. Thus less moment should be resisted at column 1 than at column 3. However, analyses (10) have shown that satisfactory designs result when the stiffness of the column is based on the gravity loads alone, with $\sum M_{B}$ resisted, in part, by equal moments $M_{1}$ and $M_{3}$, provided column reinforcement is made equal for the two exterior columns.

With dual systems consisting of walls and frames (Fig. 5(b)), force-based design based on elastic analyses (11) are found to have the wall dominating behaviour in the lower levels, and the frame dominating behaviour in the upper stories. A substitute structure analysis representing conditions at maximum displacement response is likely to result in significantly different distribution of actions between walls and frames. In the substitute structure analysis, the wall stiffness will be reduced over the lower levels in proportion to the expected ductility demand, implying more force transfer to the frames. At the upper levels the wall will be expected to remain elastic, while the beam hinges will reduce the effective stiffness of the frames, transferring forces to the wall. Although not yet confirmed by static and dynamic analysis it would appear that a displacement-based procedure would result in a more rational distribution of design actions compared with force-based approaches. More research is needed in this area.

\section{EXAMPLES OF MULTISTOREY FRAME DESIGNS}

In a recent study (10) displacement-based designs of multistorey frame buildings were investigated. The frames involved 4, 8, 12 and 20-storey examples, and were designed to the New Zealand displacement spectra for deep soft or flexible soils (Fig. 3(c)), with a peak ground acceleration of $0.5 \mathrm{~g}$.

The frames were all based on a uniform storey height of $3 \mathrm{~m}$, with two equal bays of $6 \mathrm{~m}$. Storey weight was $1,000 \mathrm{kN}$ in all cases. Material properties were $\mathrm{f}^{\prime}{ }_{\mathrm{c}}=35 \mathrm{MPa}, \mathrm{f}_{\mathrm{y}}=400$ $\mathrm{MPa}$. Initial trial designs indicated that beam depths of about $550 \mathrm{~mm}$ would be appropriate, and hence, from Eqn. 3, a yield drift of $\theta_{y}=0.011$ was predicted. This indicated that, for a code drift limit of 0.025 , displacement ductilities of the order of only $\mu_{\Delta}=2.2$, or less, would be expected. As a consequence, the effective damping was estimated to be $20 \%$, based on 5\% elastic damping, and a Takeda degrading 
stiffness (12) model for beam hinges with an unloading coefficient of 0.15 .

Results of the frame designs are summarized in Table 1. Beam designs were chosen to produce a tension reinforcement ratio of about $1.5-2 \%$, with column total reinforcement ratios of less than $4 \%$. The beam reinforcement levels slightly exceeded NZS3101 limits, which is felt to be acceptable, given the low ductility demand. Except in the 20-storey design, column reinforcement was kept constant over the building height, to allow for higher mode effects, though modest reductions would have been possible at the upper levels. Beam reinforcement ratios, and in some cases beam size, reduced with height in accordance with moment demand.

It may be seen from Table 1 that the design base shear does not increase greatly between the 4 and 12-storey buildings, though a significant increase is noted for the 20-storey building. As a consequence, member sizes are not greatly influenced by height. It would probably be prudent to increase the column size for the 20-storey building to reduce the rather high axial load ratio of about $0.5 \mathrm{f}^{\prime}{ }_{\mathrm{c}} \mathrm{A}_{\mathrm{g}}$ at the ground level.

All four designs were subjected to inelastic time-history analysis using Ruaumoko (13) with a suite of nine spectrumcompatible time-history records. Results for the 8-storey building, in terms of peak displacement vs. height are plotted in Figure 6, together with the design displacement profile. It is seen that the design profile is a good average to the suite of time-history profiles, which exhibit the expected scatter inherent in accelerograms. Similar agreement between design and response displacements were obtained for the other three buildings, with the biggest variation from the design profile being recorded for the 20 -storey building.

Table 1. Design Details for Frames Designed for 0.5 PGA.

\begin{tabular}{|c|c|c|c|c|}
\hline & \multicolumn{4}{|c|}{ BUILDING HEIGHT } \\
\hline & 4-Storey & 8-Storey & 12-Storey & 20-Storey \\
\hline Total Weight $\mathrm{W}(\mathrm{kN})$ & 4000 & 8000 & 12000 & 20000 \\
\hline Effective Mass $\mathrm{m}_{\mathrm{e}}$ (tonnes) & 340 & 662 & 1002 & 1745 \\
\hline Effective Period $\mathrm{T}_{\text {elf }}(\mathrm{sec})$ & 1.7 .1 & 2.89 & 3.75 & 4.42 \\
\hline Design Displacement $\Delta_{\mathrm{s}}(\mathrm{mm})$ & 225 & 379 & 492 & 606 \\
\hline Base Shear $V_{B}(k N)$ & 1024 & 1185 & 1384 & 2140 \\
\hline $\mathrm{V}_{\mathrm{B}} / \mathrm{W}$ & 0.26 & 0.15 & 0.12 & 0.11 \\
\hline Column Size $(\mathrm{mm} \times \mathrm{mm})$ & $500 \times 500$ & $525 \times 525$ & $575 \times 575$ & $600 \times 600$ \\
\hline Total Column Steel $\mathrm{A}_{\mathrm{sl}}\left(\mathrm{mm}^{2}, \%\right)$ & $6375,2.55$ & $5898,2.14$ & $4662,1.41$ & $11,160,3.10$ \\
\hline Beam Size $(\mathrm{mm} \times \mathrm{mm})$ & $500 \times 300$ & $500 \times 400$ & $550 \times 350$ & $625 \times 400$ \\
\hline Total Beam steel $\mathrm{A}_{\mathrm{st}}\left(\mathrm{mm}^{2}, \%\right)^{*}$ & $4830,3.21$ & $6560,3.28$ & $7045,3.66$ & $9825,3.93$ \\
\hline Elastic Period $\mathrm{T}_{\mathrm{el}}(\mathrm{sec})$ & 1.11 & 2.04 & 2.74 & 3.76 \\
\hline System ductility & 2.36 & 2.00 & 1.87 & 1.38 \\
\hline
\end{tabular}

$*^{\text {st }}$ level beams. $A_{\mathrm{st}}$ reduces with height.

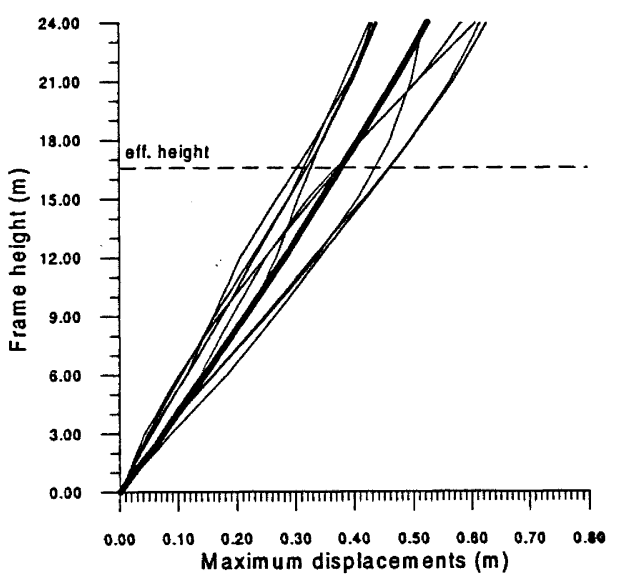

Figure 6: Design displacement profile (thick line) compared with results from suite of 5 accelerograms for 8 -storey building design.

\section{EXAMPLES OF MULTISTOREY WALL BUILDINGS}

In order to investigate direct displacement based design of wall buildings, a set of designs based on the floor plan of Fig. 7 were developed. In the direction analyzed, the seismic resistance was provided by two $6 \mathrm{~m}$ long walls and four $3 \mathrm{~m}$ walls. Eqn. 3(d) indicates that the yield curvatures, and hence yield displacements of the $3 \mathrm{~m}$ walls, will be two times that for the $6 \mathrm{~m}$ walls, and hence the displacement ductility demands, and the damping, provided by the walls will be different. The system damping was calculated using Eqn. 36. Four-storey, 8-storey, and 16-storey design examples were considered, with storey heights of $2.7 \mathrm{~m}$ in all cases. The floor slabs were considered to be rigid in-plane and flexible for transverse loading, so the walls responded as linked vertical cantilevers. Material properties of $\mathrm{f}^{\prime}{ }_{\mathrm{c}}=27.5 \mathrm{MPa}, \mathrm{f}_{\mathrm{y}}$ $=450 \mathrm{MPa}$ were assumed. Floor masses were $4,500 \mathrm{kN}$ at 
all levels, including the roof, and the wall thickness was taken as $250 \mathrm{~mm}$ in all designs. A zone factor of $\mathrm{Z}=1.2$ $(\mathrm{PGA}=0.48 \mathrm{~g})$, and the NZS4203 spectrum for deep flexible soils (Fig. 3 (c )) were used for the 4, 8 and 16-storey designs, assuming rigid foundations. In addition, the 8-storey building was also redesigned for $\mathrm{Z}=0.8(\mathrm{PGA}=0.32 \mathrm{~g}$ ), and also carried out for $\mathrm{Z}=1.2$ with flexible foundation. In this case, the foundation rotational stiffness was specified as $K_{\theta}=$ $5,430 \mathrm{MNm} /$ radian for the $6 \mathrm{~m}$ walls, and $\mathrm{K}_{\theta}=1,358$ $\mathrm{MNm} /$ radian for the $3 \mathrm{~m}$ walls. This resulted in an increase in the yield displacement of approximately $100 \%$ for the $\mathrm{Z}=$ $1.2,8$-storey building.

Note that the effect of including foundation rotational flexibility in force-based designs to NZS4203 and NZS3101 is simply to increase the fundamental period (by $41 \%$ in this case), and hence reduce the design base shear. In displacement-based design, the yield displacement (Eqn. 32(b)) and the design displacement profile (Eqn. 27) must be increased by the foundation rotational effect:

$$
\Delta_{f i}=\frac{M_{B f}}{K_{\theta}} h_{i f}
$$

where $\mathrm{M}_{\mathrm{Br}}$ is the base moment, measured at the foundation base, and $h_{\mathrm{ir}}$ is the height above the foundation base. Note that the additional elastic displacements due to foundation flexibility will reduce the displacement ductility corresponding to either of the structural (strain-based) or nonstructural (drift based) limit states, and hence will result in lower damping (see Fig. 1(d)). Hence displacement-based design can be expected to result in increased design base shear when foundation flexibility is considered. It will be noted that this is the opposite trend from that predicted by force-based design.

Maximum interstorey drift for the displacement-based designs was taken as $2.5 \%$, unless limited by the structural considerations (i.e. $\theta_{c}=0.025$, in Eqn. 18). This would imply a requirement for inelastic time-history analysis in accordance with NZS4203. Designs were performed for the damage-control limit state characterized by Eqn. 24, which assumes limit concrete and steel strains of 0.018 and 0.06 respectively. Generally, the steel limit strain governed. Wall flexural reinforcement was uniformly distributed along the wall length, with a minimum ratio of $0.25 \%$ for any wall.
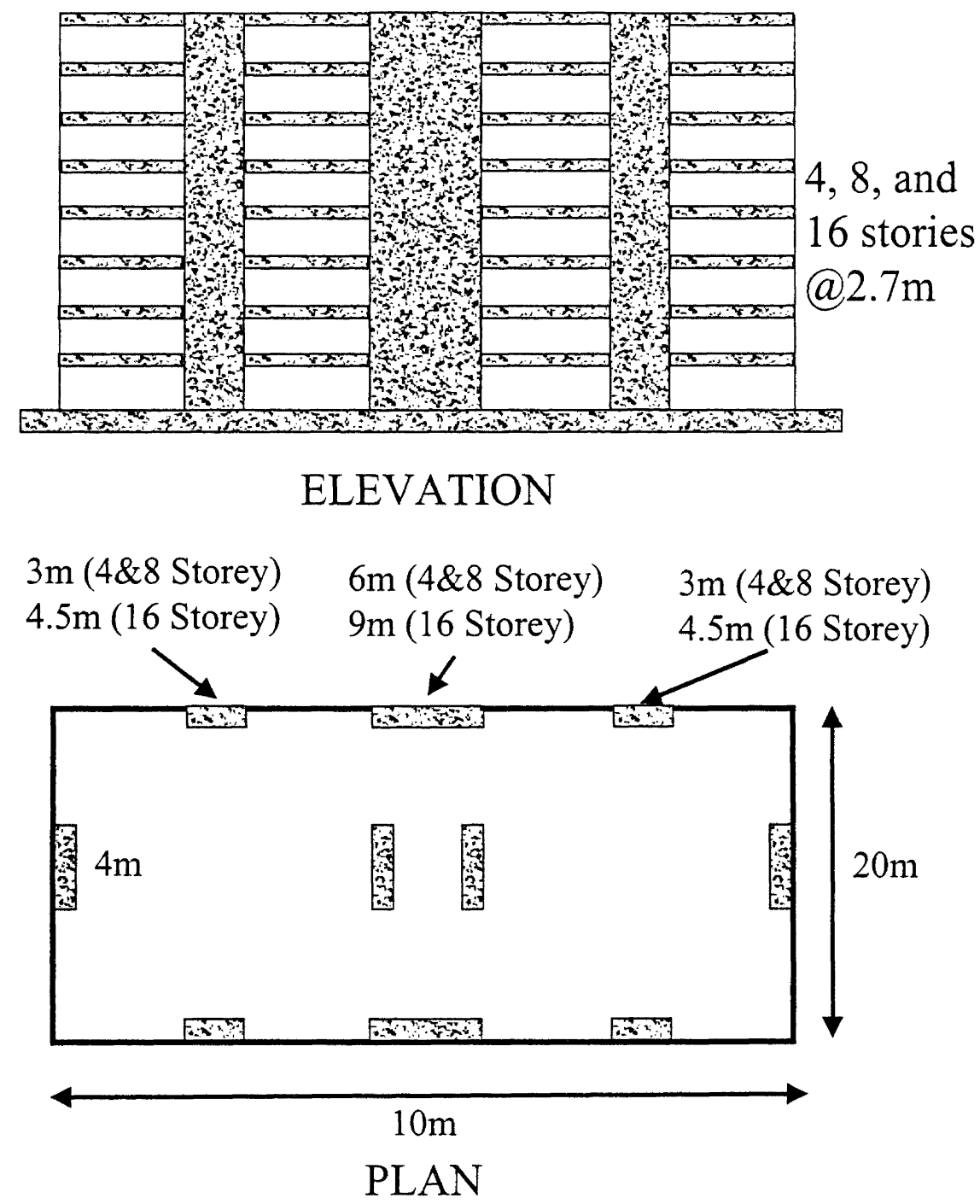

Figure 7: Example building for wall designs. 
In addition to the displacement-based design, force-based designs were also carried out. In order to have design assumptions for member strength as compatible as possible with those for the displacement based design, the following assumptions were made.

1. The flexural strength reduction factor was taken as $\phi=1.0(\phi=0.85$ would be required by NZS3101).

2. The system effective mass from the displacementbased design, given by Eqn. 29 was used for period and base shear calculations. Note that NZS4203 would require the higher value of $m_{c}=\Sigma m_{c}$ to be used for a SDOF approximation, and hence would result in higher base shear forces than resulting from these designs.

3. Cracked-section wall stiffness was taken as $35 \%$ of gross section stiffness.

4. The $S_{p}$ factor was not included in the design. Note that the $S_{p}$ factor could be considered to balance the influence of excessive mass implied in the first mode by $m_{\mathrm{e}}=\Sigma \mathrm{m}_{\mathrm{j}}$.

5. Forces were distributed between walls in proportion to the wall cracked-section elastic stiffness (i.e., in proportion to $\ell_{\mathrm{w}}{ }^{3}$ ).

6. Design ductility factor dependent on wall aspect ratio in accordance with

$$
\mu=\frac{5}{z f}
$$

where

$$
z \mathrm{f}=2.5-\frac{0.5 \mathrm{~h}_{\mathrm{w}}}{\ell_{w}} \geq 1
$$

Results comparing force-based and displacement-based solutions for the various design cases are summarized in Tables 2 to 6 . In addition, more detailed calculations outlining the design steps for the 8-storey, rigid base design for $\mathrm{Z}=1.2$ are included in an appendix.

\section{Storey Building-Rigid Foundation, $\mathrm{Z}=1.2(0.48 \mathrm{~g}$ PGA)}

Comparison of the force-based and displacement-based designs is given in Table 2 . Ductility values for the displacement-based design reflect the calculated ductility capacity for the $6 \mathrm{~m}$ wall, and the correspondingly reduced ductility demand for the $3 \mathrm{~m}$ wall at the same displacement. Note the effective system damping (including hysteretic damping) of $17.6 \%$. For this structure, the required total base shear strength, and hence the total base moment demand, for the displacement-based design (DBD) is about 38\% higher than for force-based design (FBD). This is partly attributable to the higher ductility of $\mu_{\Delta}=5$ permitted by the prescriptive FBD requirements, which appears to be unsafe, when compared to the DBD computed capacity.

Table 2 Design summary - 8 Storey Building Rigid Foundation, Zone Factor of 1.2

\begin{tabular}{|l|l|l|}
\hline Design Variable & Displacement-Based Design & Force-Based Design \\
\hline Period & $T_{e f f}=2.419 \mathrm{sec}$ & $T_{c /}=1.156 \mathrm{sec}$ \\
\hline Ductility & $\mu_{3}=2.26$ & $\mu=5$ \\
& $\mu_{6}=4.53$ & \\
\hline Damping & $\zeta=17: 6 \%$ & $\zeta=5 \%$ \\
\hline Base Shear & $V_{u}=5,955 \mathrm{kN}$ & $V_{N}=4,294 \mathrm{kN}$ \\
\hline Wall Moments & $M u_{6}=31,644 \mathrm{kNm}$ & $M u_{6}=27,380 \mathrm{kNm}$ \\
& $M u_{3}=7,911 \mathrm{kNm}$ & $M u_{3}=3,423 \mathrm{kNm}$ \\
\hline Wall Axial Loads & $P_{6}=2,400 \mathrm{kN}$ & $P_{6}=2,400 \mathrm{kN}$ \\
& $P_{3}=1,200 \mathrm{kN}$ & $P_{3}=1,200 \mathrm{kN}$ \\
\hline Longitudinal Steel Ratios & $\rho_{6}=1.30 \%$ & $\rho_{6}=1.25 \%$ \\
& $\rho_{3}=1.34 \%$ & $\rho_{3}=0.34 \%$ \\
\hline
\end{tabular}

It should also be noted when comparing the two design base moment demands that the value, $\mathbf{M}_{u}$, reported for DBD corresponds to conditions at maximum displacement, and hence maximum curvature response, and will thus contain significant strength enhancement due to strain hardening, whereas the FBD uses nominal flexural strength, $\mathbf{M}_{N}$, corresponding to $\varepsilon_{\mathrm{c}}=0.004$, with no strain hardening. This is clarified in Figure 8. The required designs thus deviate less than the apparent $38 \%$, as will become clear when final reinforcement details are compared.

A comparison of the individual required wall moment capacities indicates that, despite the $38 \%$ overall increase in base moment demand, the required flexural strength for the 6 $m$ DBD wall is only $16 \%$ higher than for FBD. This is because the $3 \mathrm{~m}$ DBD wall carries $130 \%$ higher base moment than the $3 \mathrm{~m} \mathrm{FBD}$ wall. This is a consequence of the different approach for distributing the total base shear between the walls, with shear being distributed in proportion to $\ell_{\omega}{ }^{2}$ and $\ell_{\omega}{ }^{3}$ for $\mathrm{DBD}$ and FBD respectively.

The final comparison, and the only one of real significance, is the required longitudinal reinforcement ratios for the wall. Here it is seen that the DBD $6 \mathrm{~m}$ wall only requires $4 \%$ more longitudinal reinforcement to provide the required $16 \%$ difference between FBD nominal capacity and the DBD maximum-response capacity. In these designs, momentcurvature analyses were carried out to determine the required reinforcement content to provide the necessary ultimate 
flexural strength at peak response for the DBD. A similar result would, however have been achieved by relating the nominal and ultimate flexural strength by the expression

$$
M_{N}=\frac{M_{u}}{1+r\left(\mu_{\Delta}-1\right)}
$$

where $\mu_{\Delta}$ is the design ductility of the wall at maximum response, and $r=0.03$ is the post yield stiffness ratio for the wall (see Fig. 8).

Note that despite the similarity between reinforcement content for the $6 \mathrm{~m}$ walls, the $3 \mathrm{~m}$ DBD walls have nearly four times the reinforcement ratio of the $3 \mathrm{~m}$ FBD. It is seen that FBD concentrates the seismic resistance as much as possible in the $6 \mathrm{~m}$ walls, whereas DBD makes greater use of the $3 \mathrm{~m}$ walls. Note further that since the actual ductility demands on the $3 \mathrm{~m}$ walls will be less than for the structure as a whole, the system ductility will be less than for the $6 \mathrm{~m}$ wall. This effect was directly considered in determining the required strength of the $\mathrm{DBD}$, but is not considered in FBD. As a consequence, even if the FBD was adequate, the ductility demand of the $6 \mathrm{~m}$ wall would exceed the code value of $\mu=5$.

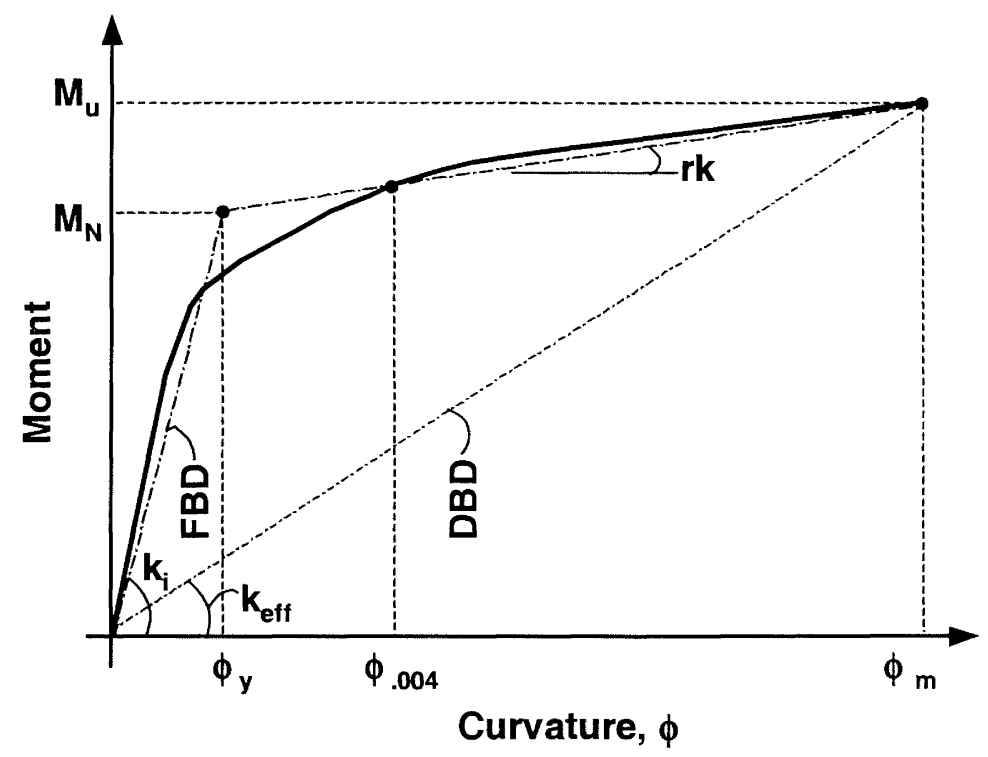

Figure 8: Design flexural strengths for force-based (FBD) and displacement-based (DBD) designs.

\section{8-Storey Building-Flexible Foundation, $\mathrm{Z}=1.2(0.48 \mathrm{~g}$ PGA)}

Results for the 8-storey building with $\mathrm{Z}=1.2$ on a flexible foundation are summarized in Table 3 . Note the increase in both elastic (FBD) and effective (DBD) period, compared with Table 2. It will be seen that the increase in period is proportionately much larger with the FBD. NZS4203 (and other codes) do not require a reduction in the design ductility for walls with significant foundation flexibility, but examination of Fig. 9 shows that since the system yield displacement increases from $\Delta_{\mathrm{y}}$ to $\Delta_{\mathrm{f}}+\Delta_{\mathrm{y}}$ as a consequence of foundation flexibility, while the plastic displacement capacity $\Delta_{p}$ is essentially independent of foundation flexibility, and hence remains constant, the displacement ductility capacity $\mu_{\Delta}$ is reduced by foundation rotation. If the effects of foundation flexibility are ignored in terms of influence on period as well as influence on ductilities, the net effect will not normally be serious. However, if the designer includes the influence of foundation flexibility on period, but ignores the reduction in ductility capacity, the results could be disastrous. Note the DBD automatically compensates for the effects of foundation flexibility on both period and ductility. The design displacement is calculated from the sum of elastic (including foundation flexibility) and plastic components, and the reduced ductility calculated by Eqn. 34 automatically results in reduced damping to the system. This is apparent in Table 3 , where the design damping is reduced from $17.6 \%$ to $14.3 \%$.

As can be seen from Table 3, the difference in required strength for FBD and DBD is dramatic, with a factor of 2 separating the design base shears. The DBD results in reinforcement contents a little less than the rigid-base design, indicating that ignoring foundation flexibility effects completely would in fact be conservative, but the very low reinforcement contents for the FBD lead us to anticipate significantly higher damage levels for this design under moderate seismic intensity.

\section{8-Storey Building, Rigid Foundation $\mathrm{Z}=0.8(0.32 \mathrm{~g}$ PGA $)$}

Comparison of Table 4 with Table 2 indicates that for FBD, the elastic period is unchanged, and the design base shear has reduced in proportion to the zone factor. For displacementbased design, the target displacements, and effective damping remain unchanged from Table 2 , and as a consequence of the reduced seismic intensity, the effective period increases, and the design base shear is reduced to only $45 \%$ of the $\mathrm{Z}=1.2$ case, even though the intensity has only reduced to $67 \%$ of 
the $\mathrm{Z}=1.2$. As a consequence, the required reinforcement ratio is significantly less than for the FBD, and redesign with smaller walls could be considered.

The apparently anomalously large decrease of required strength as seismic intensity increases bears further examination. This is illustrated in Figure 10 where acceleration spectra (Fig. 10(a)) and displacement spectra (Fig. 10(b)) are shown for two seismic zones. It is assumed that the spectral shapes for the two zones are identical and each are found by multiplying a base level spectrum by the zone factor $Z_{1}$ or $Z_{2}$.

Table 3 Design summary - 8-Storey Building Flexible Foundation, Zone Factor of 1.2

\begin{tabular}{|l|l|l|}
\hline Design Variable & Displacement-Based Design & Force-Based Design \\
\hline Period & $T_{\text {eff }}=2.785 \mathrm{sec}$ & $T_{e l}=1.75 \mathrm{sec}$ \\
\hline Ductility & $\mu_{3}=1.78$ & $\mu=5$ \\
& $\mu_{6}=2.58$ & \\
\hline Damping & $\zeta=14.3 \%$ & $\zeta=5 \%$ \\
\hline Base Shear & $V_{u}=5,762 \mathrm{kN}$ & $V_{N}=2,857 \mathrm{kN}$ \\
\hline Wall Moments & $M u_{6}=30,362 \mathrm{kNm}$ & $M n_{6}=16,629 \mathrm{kNm}$ \\
& $M u_{3}=7,591 \mathrm{kNm}$ & $M n_{3}=2,975 \mathrm{kNm}$ \\
\hline Wall Axial Loads & $P_{6}=2,400 \mathrm{kN}$ & $P_{6}=2,400 \mathrm{kN}$ \\
& $P_{3}=1,200 \mathrm{kN}$ & $P_{3}=1,200 \mathrm{kN}$ \\
\hline Longitudinal Steel Ratios & $\rho_{6}=1.21 \%$ & $\rho_{6}=0.51 \%$ \\
& $\rho_{3}=1.26 \%$ & $\rho_{3}=0.25 \%(\mathrm{nom})$. \\
\hline
\end{tabular}

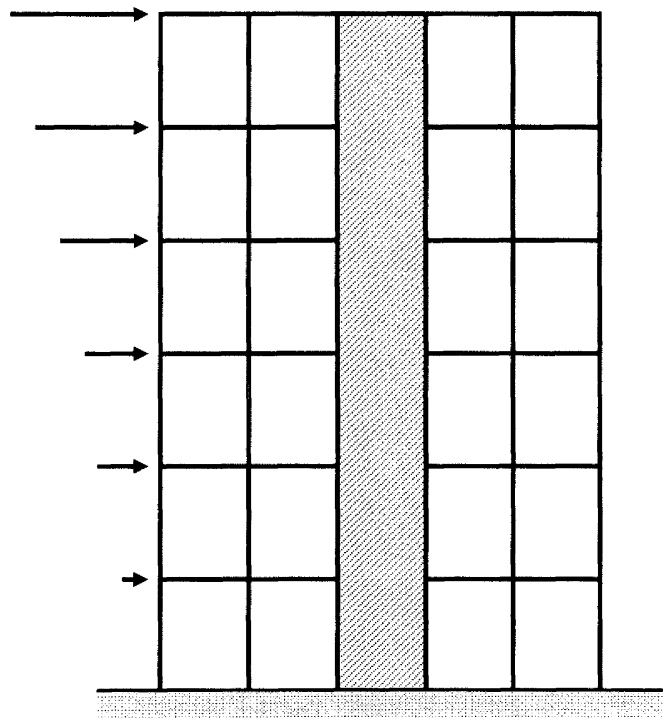

Flexible Base

(a) Building

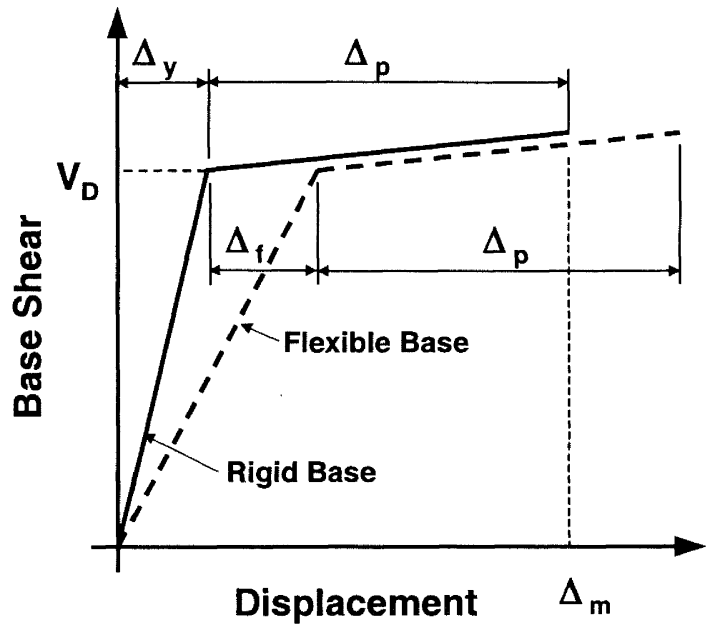

(b) Lateral Force-Displacement Response

Figure 9: Influence of foundation's rotational ductility demand on displacement ductility capacity. 
Table 4 Design Summary - 8-Storey Building Rigid Foundation, Zone Factor of 0.8

\begin{tabular}{|l|l|l|}
\hline Design Variable & Displacement-Based Design & Force-Based Design \\
\hline Period & $T_{e f f}=3.628 \mathrm{sec}$ & $T_{e l}=1.156 \mathrm{sec}$ \\
\hline Ductility & $\mu_{3}=2.26$ & $\mu=5$ \\
& $\mu_{6}=4.53$ & \\
\hline Damping & $\zeta=17.6 \%$ & $\zeta=5 \%$ \\
\hline Base Shear & $V_{u}=2,647 \mathrm{kN}$ & $V_{N}=2,863 \mathrm{kN}$ \\
\hline Wall Moments & $M u_{6}=14,064 \mathrm{kNm}$ & $M n_{6}=18,253 \mathrm{kNm}$ \\
& $M u_{3}=3,516 \mathrm{kNm}$ & $M n_{3}=2,282 \mathrm{kNm}$ \\
\hline Wall Axial Loads & $P_{6}=2,400 \mathrm{kN}$ & $P_{6}=2,400 \mathrm{kN}$ \\
& $P_{3}=1,200 \mathrm{kN}$ & $P_{3}=1,200 \mathrm{kN}$ \\
\hline Longitudinal Steel Ratios & $\rho_{6}=0.34 \%$ & $\rho_{6}=0.61 \%$ \\
& $\rho_{3}=0.31 \%$ & $\rho_{3}=0.25 \%(\mathrm{nom})$. \\
\hline
\end{tabular}

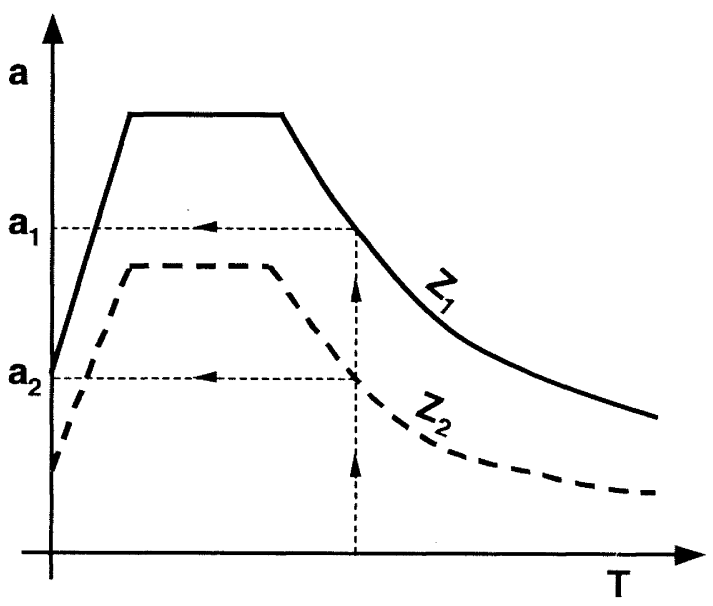

(a) Acceleration Spectra

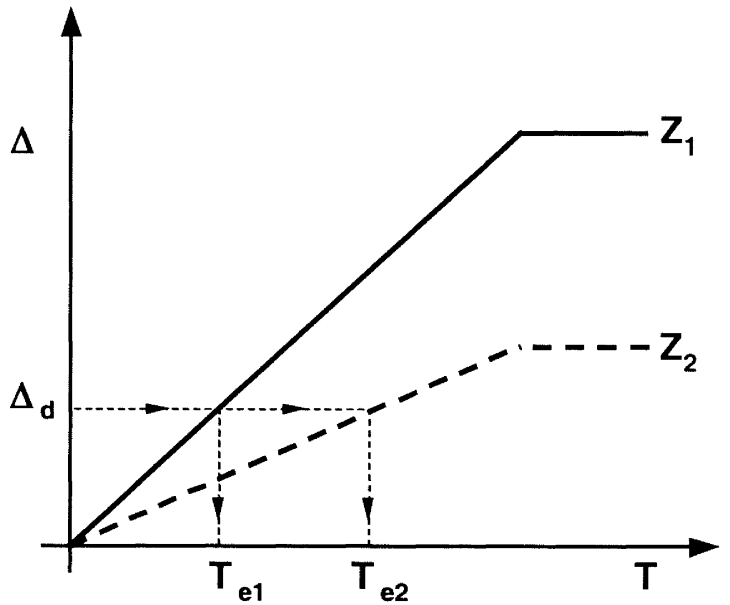

(b) Displacement Spectra

Figure 10: Influence of zone intensity on design.

Assume the structural geometry and member sizes of the designed building are the same for the $Z_{1}$ and $Z_{2}$ zones. Then, for force-based design, making normal design assumptions that the elastic period is the same for the two buildings, it is clear that the required base shear forces, $V_{b 1}$ and $\mathrm{V}_{\mathrm{b} 2}$, for the two buildings are related by

$$
V_{B 2}=V_{B 1} \frac{Z_{2}}{Z_{1}}
$$

Under direct displacement-based design, the assumption of equal geometry ensures that the yield displacements, and the limit-state design displacements for the two buildings are identical. Hence the ductility, and the damping, is also the same for the two buildings. As may be seen from Fig. 10(b), with equal design displacement and damping the effective periods $\mathrm{T}_{\mathrm{e} 1}$ and $\mathrm{T}_{\mathrm{e} 2}$ will be related to the zone intensity by

$$
T_{e 2}=T_{e 1} \frac{Z_{1}}{Z_{2}}
$$

From Eqn. 6, the required effective stiffnesses are inversely proportional to the period squared, hence

$$
K_{e 2}=K_{e 1}\left(\frac{Z_{2}}{Z_{1}}\right)^{2}
$$

Further, since the design displacements are equal, Eqn. (7) yields the base shear ratio as

$$
V_{B 2}=V_{B 1}\left(\frac{Z_{2}}{Z_{1}}\right)^{2}
$$

Thus the required strength is proportional to the square of the seismic intensity. This is a fundamentally important difference between the two approaches, particularly for regions of low seismicity. Note that this conclusion is directly implied by Eqn. 17. 


\section{4-Storey Building-Rigid Foundation $\mathrm{Z}=1.2$}

Results for this case are summarized in Table 5. In this case the FBD has slightly larger design forces that the DBD. This is largely due to the reduced ductility factor required by Eqn. 41 for the $6 \mathrm{~m}$ walls, as a consequence of their low aspect ratios. As a consequence the base shear is $41 \%$ more than for the FBD 8 storey structure.
On the other hand, the displacement-based design has a slightly smaller base shear than the 8-storey DBD design, though the $2.4 \%$ reduction is hardly significant. Note the significantly higher ductility levels for the DBD, based on limit strain calculations. Thus, again, FBD and DBD are in conflict with FBD predicting lower ductility capacity and DBD higher capacity for the more squat four storey walls (Aspect ratio $=1.8$. Because of the greater efficiency of the $\mathrm{DBD}$, reinforcement contents for the DBD walls are significantly less than for FBD.

Table 5 Design summary - 4-Storey Building Rigid Foundation, Zone Factor of 1.2

\begin{tabular}{|l|l|l|}
\hline Design Variable & Displacement-Based Design & Force-Based Design \\
\hline Period & $T_{\text {eff }}=1.223 \mathrm{sec}$ & $T_{c^{\prime}}=0.32 \mathrm{sec}$ \\
\hline Ductility & $\mu_{3}=3.94$ & $\mu=3.125$ \\
& $\mu_{6}=7.87$ & \\
\hline Damping & $\zeta=20.6 \%$ & $\zeta=5 \%$ \\
\hline Base Shear & $V_{u}=5,813 \mathrm{kN}$ & $V_{N}=6,066 \mathrm{kN}$ \\
\hline Wall Moments & $M u_{6}=16,220 \mathrm{kNm}$ & $M n_{6}=20,310 \mathrm{kNm}$ \\
& $M u_{3}=4,055 \mathrm{kNm}$ & $M n_{3}=2,539 \mathrm{kNm}$ \\
\hline Wall Axial Loads & $P_{6}=1,200 \mathrm{kN}$ & $P_{6}=1,200 \mathrm{kN}$ \\
& $P_{3}=600 \mathrm{kN}$ & $P_{3}=600 \mathrm{kN}$ \\
\hline Longitudinal Steel Ratios & $\rho_{6}=0.53 \%$ & $\rho_{6}=0.89 \%$ \\
& $\rho_{3}=0.53 \%$ & $\rho_{3}=0.29 \%$ \\
\hline
\end{tabular}

\section{6-Storey Building-Rigid Foundation, $\mathrm{Z}=1.2$}

As a final example, a 16-storey building was designed with a rigid foundation. In this case the wall lengths were increased by $50 \%$ to accommodate the expected higher moment demand. For this design the target displacement profile was dictated by the code drift limit of 0.025 rather than the structural strain limits. It is important to note that the target system displacement of $606 \mathrm{~mm}$ corresponding to the code drift limit exceeded the maximum $4 \mathrm{sec}$. spectral displacement response for $15 \%$ damping, implying that the structure would survive the code level excitation without achieving either code drift or structural strain limits However, the displacement response spectrum was conservatively assumed to extend linearly to the effective period of $4.23 \mathrm{sec}$. for the DBD structure.

Table 6 Design summary - 16-Storey Building Rigid Foundation, Zone Factor of 1.2

\begin{tabular}{|l|l|l|}
\hline Design Variable & Displacement-Based Design & Force-Based Design \\
\hline Period & $T_{e f}=4.226 \mathrm{sec}$ & $T_{e l}=1.75 \mathrm{sec}$ \\
\hline Ductility & $\mu_{4.5}=1.64$ & $\mu=5$ \\
& $\mu_{9}=3.28$ & \\
\hline Damping & $\zeta=15.2 \%$ & $\zeta=5 \%$ \\
\hline Base Shear & $V_{u}=6,974 \mathrm{kN}$ & $V_{N}=3,891 \mathrm{kN}$ \\
\hline Wall Moments & $M u_{9}=72,618 \mathrm{kNm}$ & $M n_{9}=48,616 \mathrm{kNm}$ \\
& $M u_{4.5}=18155 \mathrm{kNm}$ & $M n_{4.5}=6077 \mathrm{kNm}$ \\
\hline Wall Axial Loads & $P_{9}=4,800 \mathrm{kN}$ & $P_{9}=4,800 \mathrm{kN}$ \\
& $P_{4.5}=2,400 \mathrm{kN}$ & $P_{4.5}=2,400 \mathrm{kN}$ \\
\hline Longitudinal Steel Ratios & $\rho_{9}=1.31 \%$ & $\rho_{9}=0.73 \%$ \\
& $\rho_{4.5}=1.06 \%$ & $\rho_{4.5}=0.25 \%$ (nom.) \\
\hline
\end{tabular}


As will be seen from Table 6, the required strength for DBD was in this case significantly higher than for FBD. The expectation would be that the FBD would achieve displacements greatly exceeding the code drift limit, and redesign with increased strength would be necessary, to achieve code compliance. Note that with FBD this could only be achieved by increasing the initial stiffness, which, with current eroneous assumptions that stiffness is independent of strength, would mean increasing the wall dimensions, but not necessarily the strength. Note further that the DBD limits the deflection to the code limit by increasing the strength, and hence the stiffness of the walls, without changing their dimensions.

\section{VERIFICATION STUDIES}

\section{Verification Procedure}

Success in the displacement-based design process can be measured by comparing the actual displacement response for the design level earthquake with the target displacement profile selected in the design. Such analysis can be performed through the use of dynamic inelastic time-history analysis whereby the building is subjected to a series of time histories which are generated to fit the design response speactra. The envelope of maximum displacements at each storey can then be compared with the target displacement profile. If the analysis and target displacements match, then the intended level of damage occurred and it can be concluded that the objective of displacement-based design has been met.

Five artificial earthquake records were generated to fit the design response spectrum for 5\% damping (Fig. 3(c)) using the program SIMQKE (14). The 5\% and 15\% damped spectra of the generated earthquakes are shown along with the design response spectra in Fig. 11. Note that there is some scatter in the results, and that proportional scatter in the time-history analysis would also be expected. Also note that the actual response spectra indicated a continued upward trend beyond 4 seconds suggesting that the assumption on effective period made for the 16-storey building was valid Inelastic time-history analysis was performed using the program Ruaumoko (13). Inelastic wall elements were characterized as one-component Giberson beams with Takeda degrading stiffness, with a post-yield forcedisplacement stiffness ratio of $\mathrm{r}=0.05$, and unloading stiffness ratio of $\mu^{-0.5}$. Slabs were modelled as infinitely stiff in-plane, and infinitely flexible out-of-plane.

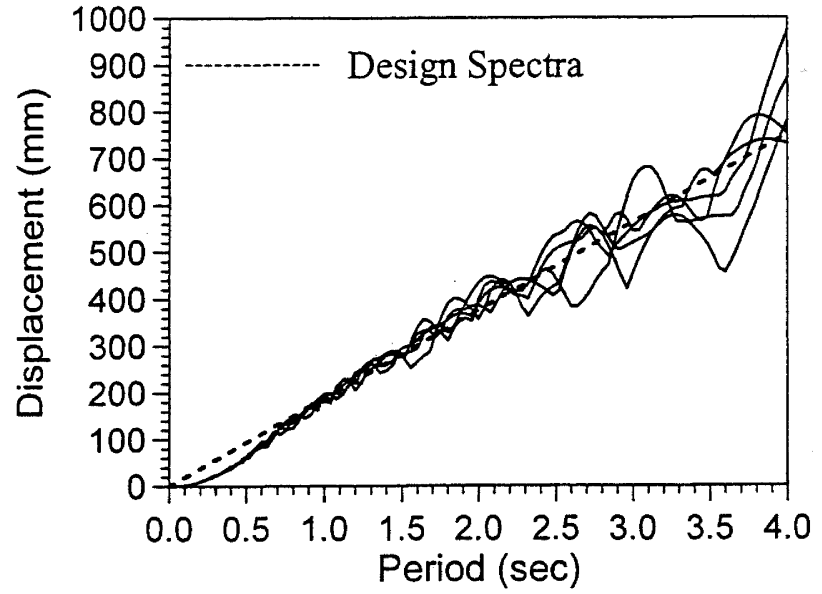

(a) $5 \%$ damping

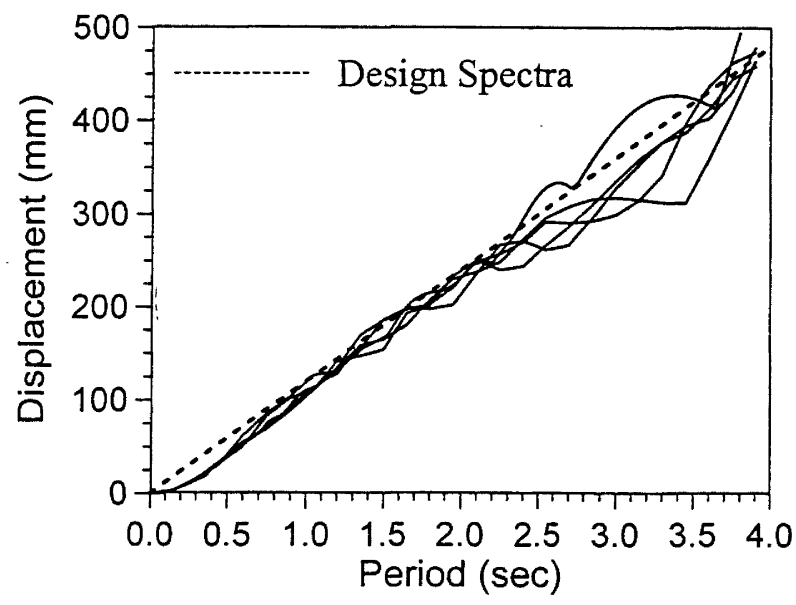

(b) $15 \%$ damping

Figure 11: Generated and design spectra comparison. 


\section{Viscous Damping in Inelastic Time History Analysis}

An issue that must be addressed in the analytical modeling is the selection of an appropriate level of viscous damping for inelastic analysis. The objective of the analytical model is to capture the assumptions made in the design as closely as possible. In the design phase, damping was comprised of two components: elastic viscous damping of 5\%, and hysteretic damping, converted to equivalent viscous damping. Hence

$$
\xi_{\text {eff }}=0.05+\xi_{h}
$$

where

$$
\xi_{h}=\frac{1-((1-r / \sqrt{\mu})-r \sqrt{\mu})}{\pi} .
$$

Note that the equivalent viscous damping is related to the degraded effective stiffness at peak response, and hence the elastic component of 5\%, also related to effective stiffness at peak response would represent a lower damping coefficient if related to the higher initial stiffness. It is thus important that in the time-history analyses, the level of viscous damping, which must be specified related to initial elastic stiffness be carefully chosen. In order to accomplish this, it is important to understand the various methods for characterizing viscous damping in time-history analyses.

There are three primary choices for modeling viscous damping in the program Ruaumoko:

\section{(1) Initial Stiffness Rayleigh Damping \\ (2) Tangent Stiffness Rayleigh Damping \\ (3) Constant Damping}

In the Rayleigh damping approach the damping matrix is a combination of mass and stiffness components, given by

$$
[\mathrm{C}]=\alpha[\mathrm{K}]+\beta[\mathrm{M}]
$$

The damping value at two different modes can be selected, and values for the constants $\alpha$ and $\beta$ determined such that the damping ratios at the predetermined periods are achieved. Damping values for the other modes will differ from the base values, with higher modes being heavily damped. The stiffness matrix can be based either on initial or tangent stiffness. Alternatively, damping can be assumed to be constant for all modes. In this study initial stiffness Rayleigh damping was adopted. The implication of using initial stiffness-proportional damping for inelastic analysis must be considered. At maximum response the effective stiffness, $\mathrm{K}_{\mathrm{eff}}$, of the structure can be calculated by Eqn. 50 where $\mathrm{K}_{\mathrm{i}}$ is the initial elastic cracked-section stiffness,

$$
K_{e f f}=\frac{K_{i}(r \mu-r+1)}{\mu}
$$

It is clear that very different damping coefficients will be obtained depending on whether $K_{i}$ or $K_{\text {eff }}$ is used in Eqn. 49. Unfortunately there is no mechanism for directly relating [C] to $\left[\mathrm{K}_{\mathrm{eff}}\right]$ in Ruaumoko (13). On the assumption that the stiffness terms have higher significance than the mass term in
Eqn. 49, it would seem reasonable to use an approximate viscous damping, related to initial stiffness, of

$$
\xi_{e l}=0.05\left[\frac{r \mu-r+1}{\mu}\right]
$$

\section{Verification of Design with $0 \%$ Viscous Damping}

The purpose of this paper is not to solve the problem of viscous damping for inelastic analysis, but rather to introduce and verify the direct displacement-based design approach. Before presenting the analytical results based on the viscous damping model previously discussed, results for a design whereby the viscous damping was set equal to $0 \%$ for the design phase of 8 storey building designed with a rigid foundation and zone factor of 1.2 are considered. Table 7 represents a summary of the $0 \%$ viscous damping design along with the design utilizing 5\% viscous damping as previously reported in Table 2 .

By performing time-history analysis on the structure designed with $0 \%$ viscous damping while specifying $0 \%$ viscous damping in the analytical model, one can remove the variable of viscous damping entirely from the verification process. As a result, this allows us to investigate the accuracy of the design approach without reference to extraneous analytical modeling problems associated with viscous damping in inelastic analysis. It is noted that this comparison is presented only for that purpose, and during the course of normal design, the contribution of viscous damping should be included. As noted from Table 7, disregarding elastic viscous damping in the design will result in design forces $30 \%$ higher than if it were included in the design.

Results of the analysis are shown in Figure 12. From this plot, it is noted that there is excellent agreement between the target and actual displacement envelope for all of the earthquake records, and that the scatter is minimal, indicating that the displacement-based design approach is very capable of specifying displacements for a particular earthquake level.

\section{Analysis Results}

Presented in this section are the results of a series of timehistory analysis performed on the buildings designed with displacement-based design. Results are presented in the form of displacement envelopes for the analytical results along with the target displacement envelope assumed in the design. The viscous damping utilized in the analysis is shown in Table 8. The values were calculated with Eqn. 50.

The results of the analysis for the 8-storey DBD building designed with a rigid base and seismic zone factor of 1.2 are shown in Figure 13(a). Note that the target displacement profile fits within the scatter of the analysis results quite well. As previously noted, scatter in the analysis is expected due to the scatter in the response spectra as shown in Figure 10. However, the results are generally very good. Figure 13(b) represents the analysis results for the same structure designed with force-based design. Note that there is no target displacement for force-based design, however, by showing the time-history analysis results of buildings designed with each method, the variation in damage achieved with forcebased design can be illustrated. Note that the displacements 
for force-based design are significantly higher than displacement-based design for this case.

The results of the DBD building designed with a flexible foundation are shown in Figure 13(c). Again, note the good agreement between the target and actual displacement envelopes.

Results for the 8-storey building designed with the rigid base to a zone factor of 0.8 are shown in Figure 13(d). Recall that the design base shear force for displacement-based design was in this case lower than for force-based design by about
15\%. The analysis results again indicate good agreement between the target and actual displacements envelopes.

Results for the 4-storey and 16-storey DBD structures for $\mathrm{Z}=$ 1.2 are presented in Fig. 14(a) and 14(b), respectively. For the 4-storey building the target displacement profile falls in the middle of the analyses results, and good agreement between target profiles and time-history results is also apparent for the 16-storey building.

The good agreement between target displacement profiles and time-history results provides an excellent verification of the DBD procedure.

Table 7 Design summary - 8-Storey Building Rigid Foundation, Zone Factor of 1.2

\begin{tabular}{|l|l|l|}
\hline Design Variable & DBD 5\% Viscous Damping & DBD 0\% Viscous Damping \\
\hline Period & $T_{\text {eff }}=2.419 \mathrm{sec}$ & $T_{e l}=2.088 \mathrm{sec}$ \\
\hline Ductility & $\mu_{3}=2.26$ & $\mu_{3}=2.26$ \\
& $\mu_{6}=4.53$ & $\mu_{6}=4.53$ \\
\hline Damping & $\zeta=17.6 \%$ & $\zeta=12.6 \%$ \\
\hline Base Shear & $V_{u}=5955 \mathrm{kN}$ & $V_{N}=7994 \mathrm{kN}$ \\
\hline Wall Moments & $M \dot{u}_{6}=31644 \mathrm{kNm}$ & $M u_{6}=42480 \mathrm{kNm}$ \\
& $M u_{3}=7911 \mathrm{kNm}$ & $M u_{3}=10620 \mathrm{kNm}$ \\
\hline Wall Axial Loads & $P_{6}=2400 \mathrm{kN}$ & $P_{6}=2400 \mathrm{kN}$ \\
& $P_{3}=1200 \mathrm{kN}$ & $P_{3}=1200 \mathrm{kN}$ \\
\hline Longitudinal Steel Ratios & $\rho_{6}=1.30 \%$ & $\rho_{6}=2.01 \%$ \\
& $\rho_{3}=1.34 \%$ & $\rho_{3}=2.15 \%$ \\
\hline
\end{tabular}

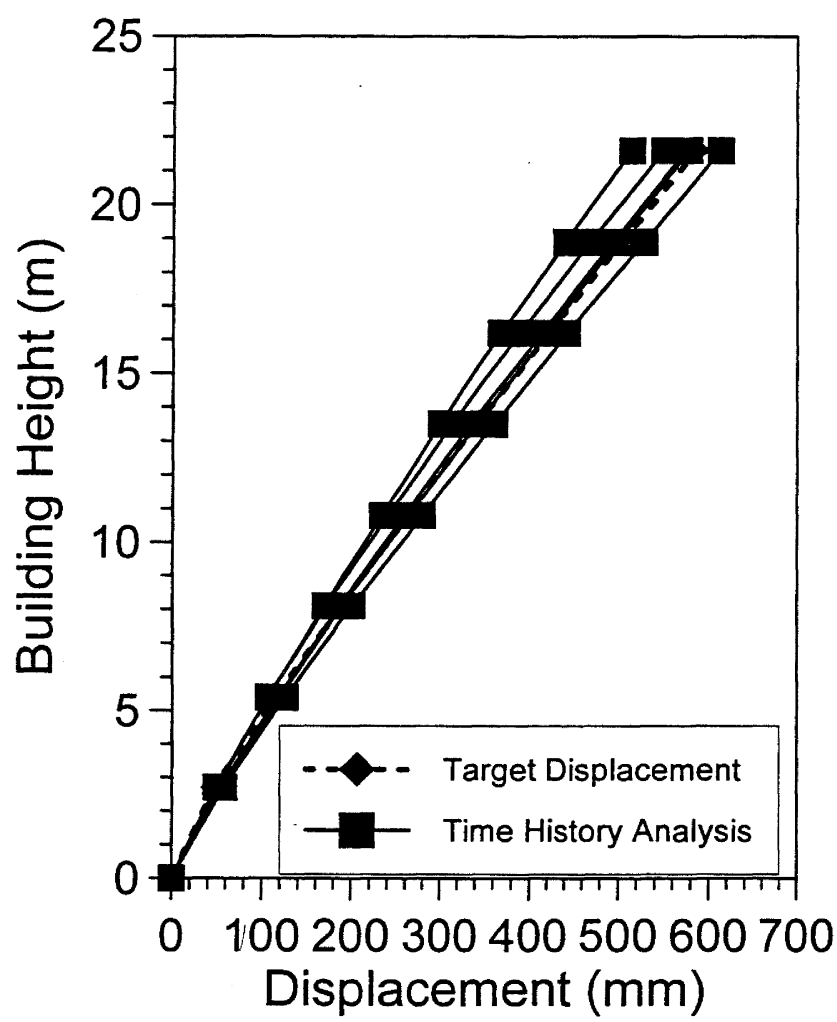

Figure 12: 8-storey building designed and analysed with 0\% viscous damping. 
Table 8 Viscous Damping Assumed For Time-History Analysis

\begin{tabular}{|l|c|c|}
\hline Building & System Ductility $\boldsymbol{\mu}$ & Analysis Viscous Damping $\boldsymbol{\zeta}$ \\
\hline 8- Storey Rigid, $\quad \mathrm{Z}=1.2$ & 3.45 & $1.6 \%$ \\
\hline 8- Storey Flexible, $\mathrm{Z}=1.2$ & 2.25 & $2.4 \%$ \\
\hline 8- Storey Rigid, $\mathrm{Z}=0.8$ & 3.45 & $1.6 \%$ \\
\hline 4- Storey Rigid, $\quad \mathrm{Z}=1.2$ & 6.02 & $1 \%$ \\
\hline 16- Storey Rigid, $\mathrm{Z}=1.2$ & 2.5 & $2.2 \%$ \\
\hline
\end{tabular}

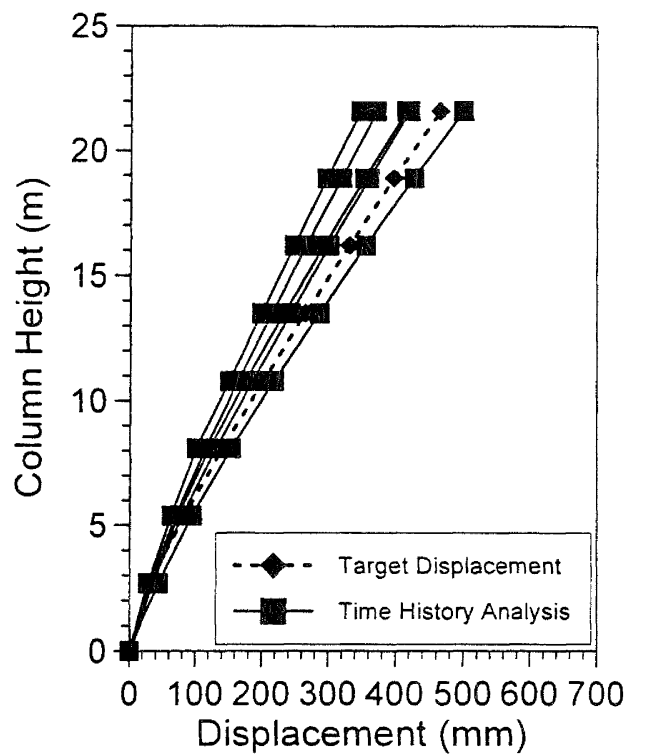

(a) DBD Rigid base $Z=1.2$

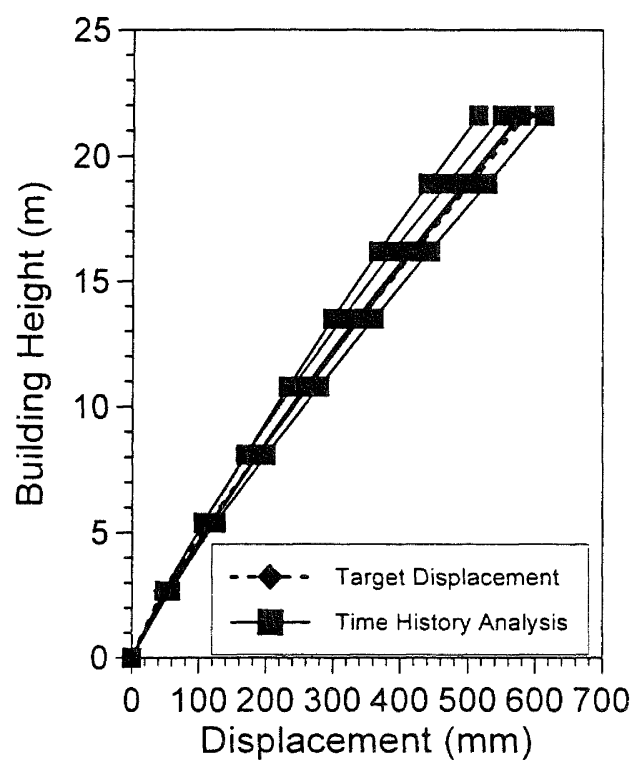

(c) DBD Flexible base $Z=1.2$

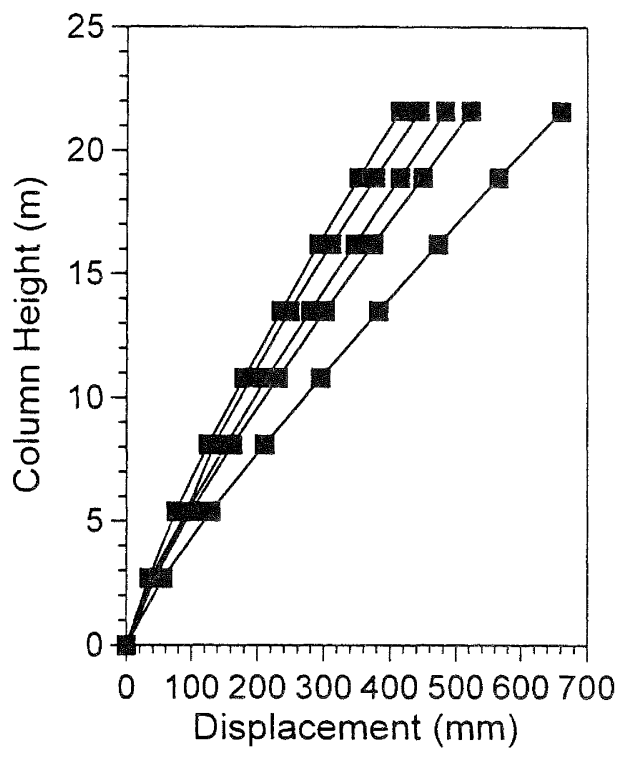

(b) FBD Rigid base $\mathrm{Z}=1.2$

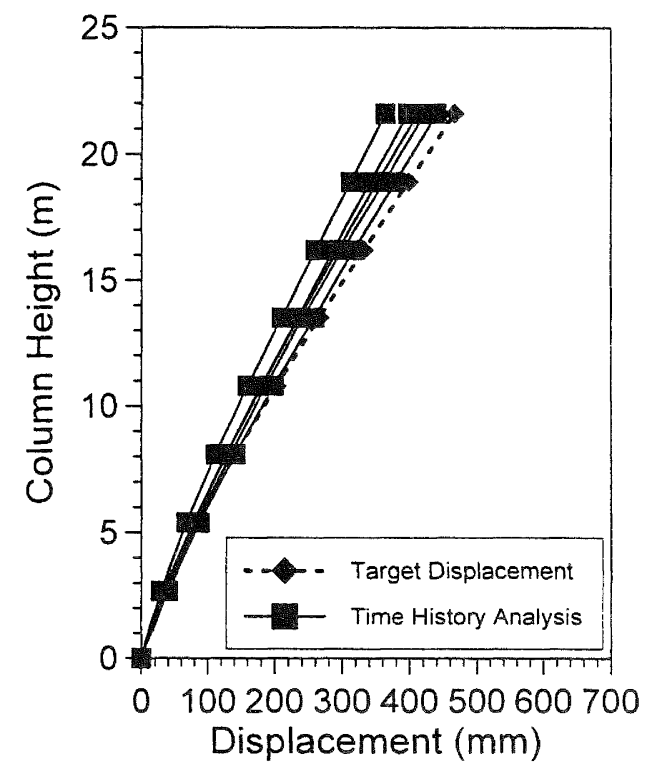

(d) DBD Rigid base $\mathrm{Z}=0.8$

Figure 13: 8-storey wall buildings - analysis results. 


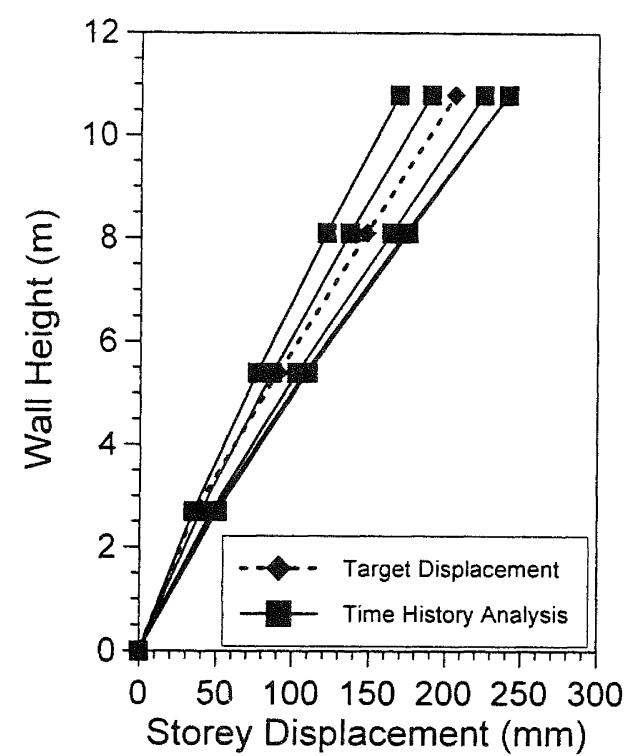

(a) 4 Storey DBD Rigid base $Z=1.2$

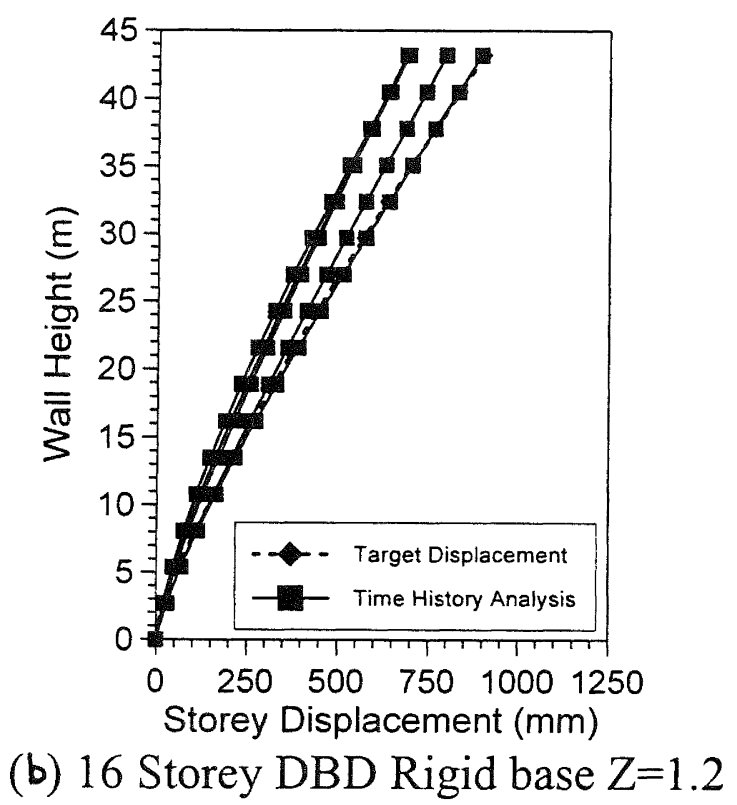

Figure 14: 4 and 6-storey buildings-analysis results.

\section{CONCLUSIONS}

This paper describes an alternative seismic design procedure for determining the required base-shear strength for buildings to achieve specified design limit states. The procedure is as simple as a single-cycle equivalent lateral force design approach, but has much greater potential for producing rational and efficient structural designs.
In the process of developing the procedure it was pointed out that current force-based design is unacceptably crude, and that this crudeness is generally incorporated in "performancebased" design procedures which add displacement checking to force-based designs. In order to carry out realistic forcebased designs, multiple iterations are necessary, regardless whether the procedure is based on the equivalent lateral force approach, or a multi-mode dynamic analysis.

A major reason why displacement-based design is fundamentally more direct than force-based design is that yield curvature of sections is essentially dependent only on yield strain and section depth. As a consequence strength and stiffness are linearly related. This simplifies displacementbased design, but complicates force-based design, if realistic estimates of building period are to be used.

The design procedure was illustrated by frame and wall examples. For the frame structures a design procedure was suggested in which the column base moments are chosen by the designer to ensure an advantageous distribution of column moments above and below the level 2 beams. This simple but rational procedure implies moderate moment redistribution between column base and beam end plastic hinges.

Wall structures between 4 and 16-storeys were designed and analysed by time-history analyses. In the displacement-based design procedure, the design ductility level is determined based on damage and drift limitations at the start of the process, with values varying between 7.9 for the critical walls of the 4-storey structure to 3.3 for the 16-storey structure. By contrast, force based design to NZS4203 and NZS3101 would specify design ductilities of 3.1 and 5.0 for the 4 and 16-storey structures, respectively.

It was shown that the influences of foundation flexibility could be simply and correctly incorporated in direct displacement-based design, but that care must be exercised when incorporating foundation flexibility into force based design, as the resulting reduction in ductility capacity is not recognized in the New Zealand design codes.

Time-history analyses of frame and wall structures designed by direct-displacement-based design showed excellent agreement with the target displacement profiles. However, care was needed in interpreting the level of elastic viscous damping to be used in the time-history analysis.

Finally, an interesting and important conclusion from displacement-based design is that required base-shear strength is proportional to the square of seismic intensity, whereas force-based design relates base-shear strength linearily to seismic intensity. Thus the required base shear strength for a building in a region with intensity $Z=0.6$ should be only $25 \%$ of that for an identical building in a region with intensity $Z=1.2$, to achieve the same level of damage.

Direct displacement based design is a procedure for determining a more rational level of seismic design strength for the plastic hinge locations of structures than that provided by current force-based procedures. It is emphasized that normal capacity design procedures to avoid undesirable hinge location and shear failure must still be implemented. 


\section{ACKNOWLEDGEMENTS}

The research leading to this paper has been partly funded by the New Zealand Earthquake Commission, through its Distinguished Earthquake Research Fellowship. This financial support is gratefully acknowledged.

\section{REFERENCES}

1. NZS4203. "Code of Practice for General Structural Design, and Design Loadings for Buildings." New Zealand Standards Association, Wellington, 1992.

2. NZS3101: 1995 Concrete Structures Standard (Parts 1 \& 2) Standards Association of New Zealand, Wellington 1995.

3. Priestley, M.J.N. and Kowalsky, M.J. "Aspects of Drift and Ductility Capacity of Cantilever Structural Walls." Bulletin, New Zealand National Society for Earthquake Engineering, Vol. 31, No. 2, June 1998, pp 73-85.

4. Priestley, M.J.N. "Brief Comments on Elastic Flexibility of Reinforced Concrete Frames, and Significance to Seismic Design." Bulletin, New Zealand National Society for Earthquake Engineering Vol. 31, No. 4, Dec. 1998, pp 246-259.

5. Shibata, A. and Sozen, M. "Substitute Structure Method for Seismic Design in Reinforced Concrete." Journal, Structural Division, ASCE Vol. 102 (6) 1976.

6. Priestley, M.J.N., Seible, F., and Calvi, G.M. "Seismic Design and Retrofit of Bridges." (John Wiley \& Sons Inc. New York) 1996, 686 pp.

7. EC8. Eurocode 9: Design Provisions for Earthquake Resistance of Structures, 1994.

8. Kowalsky, M.J., Priestley, M.J.N., and MacRae, G.A. "Displacement-based Design of R.C. Bridge Columns in Seismic Regions." Earthquake Engineering and Structural Dynamics, Vol. 24, 1995, pp. 1623-1643.

9. Calvi, G.M. and Kingsley, G.R. "Displacement-based Seismic Design of Multi-degree-of-Freedom Bridge Structures." Earthquake Engineering and Structural Dynamics, Vol. 24, 1995, pp. 1247-1266.

10. Loeding, S., Kowalsky, M.J., and Priestley, M.J.N. "Displacement-based Design Methodology Applied to R.C. Building Frames." Structural Systems Research Report SSRP 98/06, Structures Division, University of California, San Diego, 1998, 296 pp.
11. Paulay, T. and Priestley, M.J.N. "Seismic Design of Concrete and Masonry Buildings." (John Wiley \& Sons Inc. New York) 1992, 744 pp.

12. Takeda T., Sozen., and Nielsen N., "Reinforced Concrete Response to Simulated Earthquakes", Journal of the Structural Division, ASCE, 96(12) December 1970.

13. Carr, A.J. "Ruaumoko-Program for Inelastic Dynamic Analysis." Dept. of Civil Engineering, University of Canterbury, 1996.

14. Vanmarke, E.H. "SIMQKE: A Program for Artificial Motion Generation." Civil Engineering Dept. Massachusetts Institute of Technology, 1976.

\section{APPENDIX - EXAMPLE: 8-STOREY BUILDING, RIGID BASE, $Z=1.2$}

The displacement-based design procedure for structural wall buildings starts by the selection of a design limit state, seismic input, material properties, and building configuration. All of these parameters have been previously identified in the main text.

The next step involves the calculation of the design displacement profile, which comprises elastic and plastic components as shown in Eqn. 27. The displacement profile should be calculated for the longest wall since it will achieve its strain-based damage criteria before the shorter walls. For the 8 storey structural wall building, the strain limit-state based drift from Eqn. 23 is shown in Eqn. A1. Note that the maximum curvature, $\phi_{m}$, and the yield curvature, $\phi_{y}$ are obtained from Eqns. 24 and 31. The plastic hinge length, $\ell_{p}$, is obtained from the greater of Eqns. 26.

$$
\begin{aligned}
\theta_{d} & =\frac{\varepsilon_{y} h_{u}}{l_{w}}+\left(\phi_{m}-\phi_{y}\right) \ell_{p} \\
& =\frac{(0.00225)(8)(2.7)}{6}+\left(\frac{0.072}{6}-\frac{(2)(0.00225)}{6}\right) 1.848 \\
& =0.0287
\end{aligned}
$$

Eqn. Al

Since this is greater than the code allowable drift of 0.025 , the target displacement profile is obtained with Eqn. 27 where $\theta_{d}=0.025$. Also, the actual effective height is used in estimating the plastic hinge length (an iterative process that does not greatly influence the result) resulting in $\ell_{p}=1.901 \mathrm{~m}$. The target profile is shown as Eqn. A2. 
0

0.032

0.085

0.142

$\Delta_{i}=0.203$ $\mathrm{m}$

Eqn. A2

0.266

0.332

0.398

0.466

The next step involves calculation of the equivalent SDOF properties of displacement, effective mass and effective height. Using Eqns. 28, and 29, respectively, results in Eqns. $\mathrm{A} 3$, and $\mathrm{A} 4$. The effective height is taken as the height at which the system displacement (Eqn. A3) occurs. From consideration of the displaced shape, this is given by Eqn. A5. In lieu of a more detailed analysis, the effective height can be estimated with Eqn. 33 .

$$
\Delta_{d}=\frac{4500\left(\begin{array}{l}
32^{2}+85^{2}+142^{2}+203^{2}+266^{2} \\
+332^{2}+398^{2}+466^{2}
\end{array}\right)}{4500\left(\begin{array}{l}
32+85+142+203+266 \\
+332+398+466
\end{array}\right)}
$$$$
=325 \mathrm{~mm}
$$

Eqn. A3

$$
\begin{aligned}
m_{e} & =\frac{4500}{325}\left(\begin{array}{l}
32+85+142+203+266 \\
+332+398+466
\end{array}\right) \\
& =0.739 \sum m_{i} \\
& =26640 \mathrm{kN}
\end{aligned}
$$

Eqn. A4

$$
h_{\text {eff }}=15.94 \mathrm{~m}
$$

Eqn. A5

The next step involves calculation of the yield displacement, displacement ductility demand, and hence equivalent viscous damping for each wall in the building. For the $3 \mathrm{~m}$ walls, the yield displacement is shown in Eqn. A6, and the $6 \mathrm{~m}$ wall in Eqn. A7. The displacement ductility at the effective height is then given by Eqn. A8 and A9 for the $3 \mathrm{~m}$ and $6 \mathrm{~m}$ walls, respectively. The corresponding damping values are shown in Eqns. A10 and All (where $r=0.05$ ).

$$
\Delta_{y}=\frac{\phi_{y} h_{e f f}{ }^{2}}{3}\left(1.5-\frac{h_{e f f}}{2 h_{n}}\right)
$$

$3 \mathrm{~m}$ wall: $\quad=\frac{0.0015 \times 15.94^{2}}{3}\left(1.5-\frac{15.94}{2 \times 21.6}\right)$

$$
=144 \mathrm{~mm}
$$

$$
\begin{aligned}
\Delta_{y} & =\frac{\phi_{y} h_{\text {eff }}{ }^{2}}{3}\left(1.5-\frac{h_{\text {eff }}}{2 h_{n}}\right) \\
6 \mathrm{~m} \text { wall: } \quad & =\frac{0.00075 \times 15.94^{2}}{3}\left(1.5-\frac{15.94}{2 \times 21.6}\right) \\
& =72 \mathrm{~mm}
\end{aligned}
$$

Eqn. A7

Design displacement ductility, $3 \mathrm{~m}$ wall:

$$
\begin{aligned}
\mu_{\Delta} & =\frac{\Delta_{d}}{\Delta_{y}} \\
& =\frac{325}{144} \\
& =2.26
\end{aligned}
$$

Design displacement ductility, $3 \mathrm{~m}$ wall:

$$
\mu_{\Delta}=\frac{\Delta_{d}}{\Delta_{y}}
$$

$$
\begin{aligned}
& =\frac{325}{72} \\
& =4.53
\end{aligned}
$$

Design damping, $3 \mathrm{~m}$ wall

$$
\begin{aligned}
& \zeta=100\left(0.05+\frac{1-\frac{1-r}{\sqrt{\mu_{\Delta}}}-r \sqrt{\mu_{\Delta}}}{\pi}\right) \\
& =100\left(0.05+\frac{1-\frac{1-0.05}{\sqrt{2.26}}-0.05 \sqrt{2.26}}{\pi}\right) \\
& =14.34 \%
\end{aligned}
$$

Eqn. A10 
Design damping, $6 \mathrm{~m}$ wall:

$$
\begin{aligned}
& \zeta=100\left(0.05+\frac{1-\frac{1-r}{\sqrt{\mu_{\Delta}}}-r \sqrt{\mu_{\Delta}}}{\pi}\right) \\
& =100\left(0.05+\frac{1-\frac{1-0.05}{\sqrt{4.53}}-0.05 \sqrt{4.53}}{\pi}\right) \text { Eqn. A11 } \\
& =19.23 \%
\end{aligned}
$$

The system damping is then obtained from Eqn. A12.

$$
\begin{aligned}
\zeta_{e} & =\frac{3^{2} \times 14.34+6^{2} \times 19.23+3^{2} \times 14.34}{3^{2}+6^{2}+3^{2}} \\
& =17.6 \%
\end{aligned}
$$

Eqn. A12

The design base shear is then obtained from Eqn. A13 where $T_{p}=4$ and $\Delta_{p}=0.75 \mathrm{~m}$ are obtained from Fig. 3(c) (note that $\Delta_{p}$ is multiplied by $Z=1.2$ in Eqn. A13).

Note that the intermediate steps that involve çalculation of the effective period and effective stiffness at maximum response are contained within Eqn. A6. The effective period can be estimated as shown in Fig. 1(d) by entering the displacement response spectrum for $17.6 \%$ damping with the target displacement of $325 \mathrm{~mm}$ and reading down to obtain the horizontal axis. The effective period for this structure is $2.419 \mathrm{sec}$

$$
\begin{aligned}
V_{B} & =\frac{4 \pi^{2} m_{e}}{T_{p}{ }^{2}} \frac{\Delta_{p}{ }^{2}}{\Delta_{d}}\left(\frac{7}{2+\zeta}\right) \\
& =\frac{4 \pi^{2} \frac{26640000}{9.81}}{4^{2}} \frac{0.9^{2}}{0.325}\left(\frac{7}{2+17.6}\right) \text { Eqn. A13 } \\
& =5955000 \mathrm{~N}
\end{aligned}
$$

The base shear is then distributed to the walls in plan in proportion to the wall length squared as discussed in the text and shown in Eqns. Al4 and A15 for the $3 \mathrm{~m}$ and $6 \mathrm{~m}$ walls, respectively.

$$
\begin{aligned}
V_{3 m} & =\frac{3^{2}}{4 \times 3^{2}+2 \times 6^{2}} 5,955 \\
& =496 \mathrm{kN} \\
V_{6 m} & =\frac{6^{2}}{4 \times 3^{2}+2 \times 6^{2}} 5,955 \\
& =1,985 \mathrm{kN}
\end{aligned}
$$

Eqn. A14

Eqn. A 15

The required maximum moment capacity is then obtained by multiplying the base shear by the effective height (Eqn. A5), resulting in moment demands as shown in Eqns. A16 and A17 for the $3 \mathrm{~m}$ and $6 \mathrm{~m}$ walls, respectively.

$$
\begin{aligned}
M_{3 m} & =V_{3 m} h_{e f f} \\
& =496 \times 15.94 \\
& =7,911 \mathrm{kNm}
\end{aligned}
$$

$$
\begin{aligned}
M_{6 m} & =V_{6 m} h_{\text {eff }} \\
& =1,985 \times 15.94 \\
& =31,644 \mathrm{kNm}
\end{aligned}
$$

The walls are then designed to achieve the required moment capacity at the design concrete compression strain through the use of moment curvature analysis. The final analysis are shown in Tables Al and A2 for the $3 \mathrm{~m}$ and $6 \mathrm{~m}$ walls, respectively. The longitudinal steel ratio for the $3 \mathrm{~m}$ walls is $1.34 \%$ and $1.30 \%$ for the $6 \mathrm{~m}$ walls, as shown in Table 2 . The wall yield moments can be obtained by Eqn. 42 with the result being $7,441 \mathrm{kNm}$ and $26,900 \mathrm{kNm}$, respectively. 
Table A1 - Moment Curvature Analysis for $3 \mathrm{~m}$ wall

\begin{tabular}{|l|l|l|l|l|}
\hline $\begin{array}{l}\text { Concrete } \\
\text { Strain }\end{array}$ & NA Depth $(\mathbf{m m})$ & Steel Strain & Moment (kNm) & Curvature (1/m) \\
\hline 0 & 0 & 0 & 0 & 0 \\
\hline 0.0005 & 1055 & 0.00090 & 2504 & 0.00047 \\
\hline 0.0007 & 957 & 0.00146 & 3346 & 0.00073 \\
\hline 0.001 & 899 & 0.00228 & 4542 & 0.00111 \\
\hline 0.0015 & 828 & 0.00384 & 5764 & 0.00181 \\
\hline 0.002 & 764 & 0.00572 & 6284 & 0.00262 \\
\hline 0.003 & 685 & 0.00991 & 6749 & 0.00438 \\
\hline 0.004 & 655 & 0.01401 & 7055 & 0.00611 \\
\hline 0.006 & 655 & 0.02102 & 7332 & 0.00917 \\
\hline 0.008 & 673 & 0.02708 & 7457 & 0.01190 \\
\hline 0.010 & 683 & 0.03318 & 7601 & 0.01465 \\
\hline 0.012 & 695 & 0.03886 & 7703 & 0.01726 \\
\hline 0.014 & 707 & 0.04441 & 7780 & 0.01982 \\
\hline 0.016 & 714 & 0.05004 & 7852 & 0.02241 \\
\hline 0.018 & 725 & 0.05523 & 7903 & 0.02484 \\
\hline 0.020 & 736 & 0.06013 & 7939 & 0.02719 \\
\hline & & & & \\
\hline
\end{tabular}

Table A2 - Moment Curvature Analysis for $6 \mathrm{~m}$ wall

\begin{tabular}{|l|l|l|l|l|}
\hline $\begin{array}{l}\text { Concrete } \\
\text { Strain }\end{array}$ & NA Depth $(\mathbf{m m})$ & Steel Strain & Moment $(\mathbf{k N m})$ & Curvature (1/m) \\
\hline 0 & 0 & 0 & 0 & 0 \\
\hline 0.0005 & 2102 & 0.00092 & 10020 & 0.00024 \\
\hline 0.0007 & 1903 & 0.00149 & 13397 & 0.00037 \\
\hline 0.001 & 1785 & 0.00233 & 18207 & 0.00056 \\
\hline 0.0015 & 1630 & 0.00398 & 22869 & 0.00092 \\
\hline 0.002 & 1494 & 0.00596 & 24878 & 0.00134 \\
\hline 0.003 & 1331 & 0.01040 & 26747 & 0.00225 \\
\hline 0.004 & 1269 & 0.01475 & 27997 & 0.00315 \\
\hline 0.006 & 1260 & 0.02233 & 29291 & 0.00476 \\
\hline 0.008 & 1292 & 0.02883 & 29882 & 0.00619 \\
\hline 0.010 & 1317 & 0.03513 & 30404 & 0.00759 \\
\hline 0.012 & 1341 & 0.04120 & 30838 & 0.00895 \\
\hline 0.014 & 1365 & 0.04702 & 31122 & 0.01026 \\
\hline 0.016 & 1378 & 0.05302 & 31428 & 0.01160 \\
\hline 0.018 & 1395 & 0.05876 & 31641 & 0.01291 \\
\hline 0.020 & 1420 & 0.06375 & 31751 & 0.01408 \\
\hline
\end{tabular}

